Review

\title{
About Supersonic Flight and Mach 3 Flying
}

\author{
Relly Victoria Virgil Petrescu \\ ARoTMM-IFToMM, Bucharest Polytechnic University, Bucharest, (CE) Romania
}

\author{
Article history \\ Received: $13-08-2020$ \\ Revised: 22-08-2020 \\ Accepted: 28-08-2020 \\ Email: rvvpetrescu@gmail.com
}

Abstract: Aerospace-BAC Concorde was a supersonic passenger aircraft. It was the result of a government treaty between the French and British governments, combining the efforts of Aerospace and British Aircraft Corporation. With only 20 aircraft built in total, the cost of the development phase was a major economic failure. In addition, Air France and British Airways were subsidized by the government to buy the aircraft. Of the commercial supersonic aircraft, Concorde was the most successful, with the Tupolev Tu-144 being the other aircraft. The Tu-144 had a higher top speed, but the consumption was higher and the autonomy was lower than the Concorde. Flying for the first time in 1969, Concorde began its commercial service in 1976 and continued for 27 years. It operated transatlantic flights from Heathrow, London (British Airways) and Charles de Gaulle, Paris (Air France) to JFK, New York and Dulles, Washington; flying at record speeds, it travels these distances in less than half the time of other planes. Concorde also set other records, including the official FAI world record "Westbound Around the World" and "Eastbound Around the World" at speed. Following the sole accident on 25 July 2000, the economic effects following the events of 11 September 2001 and other factors, the flights ceased on 24 October 2003. The last flight took place on 24 November of the same year. Many of the problems were overcome during the research and development of the Concorde project. During the flight, the fuel was moved to optimally position the center of gravity relative to the center of pressure at a certain phase of the flight: At subsonic speeds in front, at supersonic speeds in the rear. The shape of the wings was designed to reduce the effect of this change in forces. A very important feature was its maneuverability. Concorde had the characteristics of a fighter jet that could decelerate very quickly from Mach 1.9 to Mach 0.7 in $20 \mathrm{sec}$. Concorde was so flexible that in extreme cases he could avoid avoidance. A single accident to the fastest, safest and best aircraft in human history has led to its decommissioning and the slowdown of Mach programs. However, after a certain period, these supersonic programs were resumed all over the world because the need for modern, fast flights was growing, the requirements were also more pressing. Supersonic aerodynamics are simpler than subsonic aerodynamics because air sheets at different points along the plane cannot affect each other. Supersonic jets and rocket vehicles require several times more traction to fire through the additional aerodynamic traction experienced in the transonic region (around Mach 0.85-1.2). At these speeds, aerospace engineers can easily guide the air around the aircraft's fuselage without producing new shock waves, but any change in the transverse area away from the vehicle leads to shock waves throughout the body. Designers use the supersonic surface rule and the Whitcomb area rule to minimize sudden changes in size.

Keywords: Mach 3, Concorde, Aerospace, Aircraft, British Airways 


\section{Introduction}

The aircraft is an aerodrome with a fixed load-bearing surface that provides lift due to the speed of travel. The travel speed can be ensured either by the action of powertrains or by the action of a weight component (in the case of lower flight or non-powered flight).

Appearing in the early twentieth century, the first aircraft required a lot of courage and skill to fly them. At the time, they were neither fast nor roomy. The first controlled, propelled flight with a heavier-than-air aircraft was made by the Wright Brothers on December 17, 1903, the first effective self-propelled flight was made by Traian Vuia on March 18, 1906 and the first official self-propelled flight was made by Alberto Santos-Dumont on November 12, 1906. Henri Coandă is the inventor of the propellerless aircraft, which is powered by a jet engine. Louis Blériot was the first pilot to cross the English Channel in 1909. Charles Lindbergh made the first crossing of the Atlantic, alone and nonstop, in 1927. In 1933, the Wiley Post was the first pilot to fly alone around the world. It covered $25,000 \mathrm{~km}$ in 7 days, $18 \mathrm{~h}$ and $49 \mathrm{~min}$.

An aircraft in flight acts on four forces that must be in balance. A force can generally be interpreted as a pull or push on an object in a certain direction.

Weight is a force always directed towards the center of the Earth. It is directly proportional to the mass of the plane and depends on its load. Although it is distributed over the entire device, we can imagine that it is collected and acts on a single point, called the center of gravity. In-flight, although the aircraft rotates around the center of gravity, the orientation of the weight remains toward the center of the earth. During the flight, the weight decreases constantly due to the consumption of fuel in the tanks. The weight distribution and center of gravity can also change, so the pilot must constantly adjust the controls to keep the aircraft in balance.

Traction is provided by the propulsion system. The value of traction depends on several factors associated with the propulsion system: Engine type, number of engines, engine control, speed and flight altitude. In the next figure, the two engines of the aircraft are arranged under the wings and oriented parallel to the fuselage, so the traction will act on the longitudinal centerline of the fuselage. On some aircraft (e.g., Hawker-Siddeley Harrier/Harrier) the direction of traction may vary depending on the evolution it performs. For example, when taking off, it is oriented at a certain angle to the longitudinal axis of the plane, in order to "help" the plane to take off. However, in turbojet planes, although the flue gases are discharged in the opposite direction to the flight direction, this causes the aircraft to be "pushed" forward, on the principle of action-reaction described by Newton: Any force of action is opposed by an equal force., \& the opposite direction called reaction.
Strength (movement) is the aerodynamic force that opposes anybody moving in a fluid. The size of this force is influenced by several factors: The shape of the aircraft, the density and composition of the air, the speed. The direction of this force is always opposite to the direction of flight and we can consider that it "focuses" on a single point, called the center of pressure.

The lift is the force that keeps the plane in the air and must be understood in relation to the other three. It can be generated from any part of the aircraft, but in an ordinary aircraft, the lift is mainly due to the wing and in particular to the specific shape of the wing section. Lift is an aerodynamic force due to the "passage" of an object through a fluid. It acts on the center of pressure and is defined as perpendicular to the direction of flow of the fluid.

Theories about load-bearing generation have become a source of controversy and a hot topic of discussion. Although the exact and complete explanation is quite difficult to understand without the proper mathematical apparatus, this article tries to set out its principles.

Changing the direction or speed of a fluid flow generates a force. Specifically, lift occurs when the flow of a fluid is "turned" by a solid object. When the flow is deflected in a certain direction, the lift appears in the opposite direction, in accordance with Newton's principle of action and reaction. Because air is a fluid, molecules are free to move and any solid surface can deflect flow. For a wing section - called aerodynamic profile - both its surfaces, top - extrados and bottom - intrados respectively contribute to the return of flow. Taking into account only one of the surfaces, we arrive at an incorrect theory of lift, so they are approached together.

When two solid objects interact in a mechanical process, the forces are transmitted or applied at a "point of contact". But when a solid body interacts with a fluid, things are much harder to describe, due to the fact that the fluid changes its shape. For a solid that is immersed in a fluid, the point of contact is any point on the surface of the solid. So we are dealing with a distributed force, that is, with a pressure.

The value of a force acting on a surface is equal to the pressure multiplied by the area of that surface. The pressure is a scalar unit related to the distribution of pressure in the fluid. A force is a vector unit, which has value and direction, so the direction of the force must be determined. The pressure acts perpendicularly or normally on the surface of a solid body, so the direction of the force on a very small surface of the object is normal to the surface. The normal direction changes along with the profile because it has a curved surface. In order to obtain the net mechanical force, the contributions of the components of all the small surfaces of the object must be added over the entire profile. It is important to know that if the pressure on a closed surface 
is constant, then there is no resultant force because the sum of all small forces in normal directions gives the value zero (For each small surface, there is another small surface whose normal is oriented in exactly the opposite direction to the normal of the first surface).

On a body in a moving fluid, the speed will have different values at different points along the closed surface of the body. The local pressure (given by those small strong surfaces we were talking about) being in direct relation with the local speed, it also results that it will vary along the closed surface. Adding all the normal local pressures and then multiplying by the total outer surface of the body will result in a force. The component of this force perpendicular to the direction of flow of the fluid is called the load-bearing force and the component along the direction of flow is called the forward resistance. In reality, there is only one force, caused by the variation of the pressure around the body surface or speaking of aerodynamic profiles - it is caused by the difference between the pressures on the soffit and the extrados of the profile, respectively. The aerodynamic force acts at a point determined by the pressure distribution, a point called the center of pressure.

The lift is a mechanical force, generated by the interaction and contact between a solid and a fluid. It is not generated by a force field such as weight, which is generated by the gravitational field, where one body can interact on another body without being in actual physical contact. To have lift, the solid body must be in direct contact with the fluid. So if there is no fluid, there is no movement.

On the other hand, the lift is generated by the speed difference between the solid and fluid bodies. There must be a movement between the object and the fluid. So if there is no movement, we can't talk about lift. It doesn't matter if the fluid is moving and the body is static, or if the body is moving in the fluid.

The factors that influence the lift are the shape and size of the object, its speed and the main direction of movement towards the fluid, the density of the fluid, its compressibility and its viscosity.

The external shape of the aircraft, the dimensions, the engine, the structural organization of its components directly influences its performance.

In general, an aircraft consists of the following main parts: The wing with its support devices, the fuselage, the horizontal and vertical tailings with their moving parts, the landing gear and the propulsion system. The moving parts of the aircraft are ailerons, depth, direction, flaps, flaps, aerodynamic brake and compensators.

The onboard equipment consists of flight control systems, engine operation control systems, air navigation systems, radio/radiolocation equipment.

To the military aircraft are added the flight weapons, the bombing and missile guidance installations, the protective armor, the anchorages and the equipment suitable for the combat missions.

The controls of the aircraft are actuated by hydraulic and pneumatic installations. Essential for the flight of the plane is also the fuel and oil supply installations, the electrical, antifreeze (defrosting), sanitary, thermal and sound insulation installations, air conditioning and the controls of the aircraft aggregates, the steering equipment.

The control of the propulsion system and the controls of its moving parts ensures the handling of the aircraft.

Traction control is achieved by the throttle lever that drives the propulsion system. The controls of the moving parts are ensured by the sleeve, boom, flaps, brakes, etc. For example, operating the handle back and forth commands the burrs of the depths up and down, which leads to a movement of the plane up or down. The movement of the handle to the left or right controls the ailerons on the wings, leading to a rolling movement (rotation) around the longitudinal axis. Pressing the boom pedals to the left or right activates the direction of the aircraft to the side. What must be remembered is that the handling of the aircraft is done by the combined operation of the various controls.

In aerodynamic flight, based on load-bearing force, the most important part of the aircraft is the wing. Together with the fins, the wing ensures the support, stability and maneuverability of the aircraft. In general, the wing is composed of the resistance structure, outer shell, integrated fuel tanks, hydro-pneumatic equipment related to the controls. The main landing gear of the aircraft, the propulsion system, special rocket hooks, bombs, or expandable tanks is installed under the wing.

The constructive elements of an ordinary aircraft wing are the side members, the smooths, the ribs, the cover panels and other components, of stiffening (ex: Uprights) used for transmitting the efforts between the wing and the fuselage or between the sections of the wing.

The wings with at least two struts, together with the shell form the resistance caisson, which has the task of taking over the aerodynamic and mechanical efforts to which the wing is subjected.

The side members are stiffening elements placed along the wing, which take over most of the forces and moments acting on it. They have the appearance of a reinforced beam made of soles (corner profiles) and heart (flat band), joined together with rivets. They are usually made of materials resistant to bending and twisting: Duralumin, titanium, special steels.

The ribs are elements of transverse stiffening of the wing, usually mounted perpendicular to the leading edge of the wing. The nerves have the role of preserving the shape of the wing and transmitting the aerodynamic stresses to the side members and smooth. They can be simple ribs or force ribs, the latter having the additional 
role of taking over the concentrated forces due to the various equipment and installations attached to the wings.

Smoothes are stiffening elements mounted along the wing in order to take over the axial stresses due to the bending of the wing. They must be resistant to stretching and compression and increase the resistance of the coating to deformation. They are obtained technologically by extrusion or bending and are made of duralumin, titanium-based alloys, or stainless steel.

The shell of the wing has the role of maintaining its shape and is made of duralumin sheet or alloys based on titanium, magnesium, etc. The coating is required for bending and twisting efforts. They are attached to the other elements by rivets. If the distance between the lyses is small, a corrugated sheet is used to stiffen the coating. The joining of the corrugated sheet with the coating can be done by the welding method, not by riveting. If the wing is small, the cover can be made of monolithic panels. The construction of such a wing is done by joining the panels in one piece. With very small thickness wings, the interior space no longer includes stiffening elements but is filled with honeycomb structure or other composite material, resulting in a compact structure with high mechanical strength.

The fuselage (French fuselage) is the part of the aircraft in which the cockpit, passenger cabin, cargo and most of the flight equipment and installations are placed. It represents the central body to which the wings, the tail and the landing gear are connected. The fuselage must have a minimum forward resistance. That is why its shape must be aerodynamic, have as few prominences as possible, the surface "washed" by the air stream must be well finished and with as few undulations as possible.

Hull-type fuselages are currently the most used in aerospace construction, they were definitely imposed with the advent of turbojet engines. The main elements of hull-type fuselages are the longitudinal structure formed by side members and smooth, the transverse structure formed by frames and the resistant shell.

Two types of hull fuselages are currently used in aircraft:

- Semimonococcus with a structure consisting of strong side members and a rare network of smooth and thin shells

- Semi-hull, the structure consisting of a dense network of lyses, false side members (stiffened lyses) and thin shell

The hull-type fuselages are stiffened by means of walls and floors which, together with the rest of the structure, form various compartments used for the placement of on-board equipment and installations, for the storage of transport cargo.

Tailings are devices that represent the balance, stability and control for the aircraft. The maneuverability of the aircraft largely depends on how they are built. They have fixed parts and moving parts (the moving parts being controlled by the pilot), usually located at the rear of the fuselage, which ensures the balance of the aircraft, increases stability and maneuverability and allows the change of flight direction.

They usually consist of:

- The horizontal tail, consisting of the stabilizer (fixed part) and the depth (movable part), serving to orient and direct the aircraft in the vertical plane

- Vertical tail, consisting of drift (fixed part) and direction (moving part), serving to orient and steer the aircraft horizontally

Supersonic aircraft sometimes have two vertical tailings installed and the stabilizer has only a moving part, being made in one piece. In the classic configuration, the stabilizer is placed behind the wing, but in modern fighter planes it can appear in front of it, resulting in the so-called duck configuration ("duck") (for example in Eurofighter).

In other modern aircraft, both tailings may be missing, the wing taking over the full stabilization and control roles (for example in the B-2 Spirit), by using control surfaces called ailerons.

The construction of the fins generally follows the construction schemes of the wing.

Below are two of the most widely used engines currently used to propel aircraft: Single jet engine (MTR) and dual jet engine (MTRDF).

The turbojet engine is the engine that currently equips aircraft flying at high altitudes and speeds above $0.6 \mathrm{Mach}$. Its principle of operation is as follows: The air entering through the intake device is compressed by the compressor, enters the combustion chamber where it forms together with the injected fuel the flue gas mixture and the actual combustion takes place. The flue gases then pass through the turbine, where they are partially expanded by rotation, then pass through the reaction nozzle and leave the system with kinetic energy much higher than the input, thus ensuring the traction component of the aircraft. Eventually, in supersonic planes, we can meet the afterburner system. It is incorporated in the exhaust system and has the role of injecting a new dose of fuel into the flue gas mixture coming from the combustion chamber. The new mixture burns once more, resulting in a considerable increase in traction.

Dual-flow turbojet engines - generically called turbofans - are actually modified turbojets. They are characterized by the existence of two parallel flow flows: A secondary one, of air, driven by a fan mounted on the same shaft with the low-pressure compressor of the turbine, which covers the primary (internal) airflow formed by flue gases. The MTR-DF traction is the sum 
of the tractions resulting from the two flows. We must not forget that the fan acts as propulsion, acting as a propeller. An MTR-DF system is shown in the accompanying drawings.

It should be noted that dual-flow turbojet engines are the most common types of aviation engines, equipping most civilian aircraft and a large proportion of military aircraft.

Man has wanted and dreamed of flying for a very long time, but the technologies of that time did not allow him to do such a thing and only for this reason did the epic of human flight last so long, which is now in full development and not only at one end of the road, or at a crossroads. Today, humanity has evolved a lot in all technical fields and obviously one of the main areas of aviation has evolved even more than the other top technical fields, such as nuclear energy with nuclear energy in the lead, weapons of all kinds, bioengineering, electronics, automation, robotics ...

In the future we will be able to use interspatial flight together with robotics to conquer space for humanity and to launch into the race to occupy galaxies, an extension race of human species, which although slightly delayed is still somewhat in normal parameters, because 30 years ago we didn't even know how to fly properly and only now have we learned, practiced and innovated.

Initially, the space race was started by the USA and Canada, seconded by Great Britain, due to the first Soviet attempts to start something like this, which determined the Americans to get to work, to be ambitious and to start.

Just as the road to the development of human flight was long and difficult, so was the path to the conquest of outer space. In fact, it is the conquest of outer space that gave the real start to an evolved flight, even if not immediately after the creation of NASA, but a little later. We could say that the first space shuttles were just simple space carts, but they also had their well-established purpose throughout the evolution of modern flight.

After realizing the human dream of flying, it was normal to want to do it as fast as possible.

That's how the race for faster flights started and the desire to be in first place at the speed of overtaking.

There was also a permanent race and a competition between the USA and Russia, as the first two countries which were more able to develop and support strong and faster ships so that many times when the Americans launched a fast model and the Russians came immediately with an own model faster.

The arms race often meant a race to build the fastest spaceship.

We do not want to develop this idea and show how along with the USA were the UK and Canada and then France, Italy, Germany, South Korea, China and India entered the race and more recently Iran, not necessarily along with the USA or Russia.
The present paper tries to present some aspects of the development of modern, fast, air and space ships, by selecting some that have been more remarkable and that is of more special interest.

An undeclared competition for high flight speeds also took place and to the commercial passenger ships.

Aerospace-BAC Concorde was a supersonic passenger aircraft. It was the result of a government treaty between the French and British governments, combining the efforts of Aerospace and British Aircraft Corporation. With only 20 aircraft built in total, the cost of the development phase was a major economic failure. In addition, Air France and British Airways were subsidized by the government to buy the aircraft. Of the commercial supersonic aircraft, Concorde was the most successful, with the Tupolev Tu-144 being the other aircraft. The Tu-144 had a higher top speed, but the consumption was higher and the autonomy was lower than the Concorde.

Flying for the first time in 1969, Concorde began its commercial service in 1976 and continued for 27 years. It operated transatlantic flights from Heathrow, London (British Airways) and Charles de Gaulle, Paris (Air France) to JFK, New York and Dulles, Washington; flying at record speeds, it travels these distances in less than half the time of other planes. Concorde also set other records, including the official FAI world record "Westbound Around the World" and "Eastbound Around the World" at speed.

Following the sole accident on 25 July 2000, the economic effects following the events of 11 September 2001 and other factors, the flights ceased on 24 October 2003. The last flight took place on 24 November of the same year.

In the late 1950s, the United Kingdom, France, the United States and the Soviet Union were considering air transportation at supersonic speeds. Both the British Bristol Airplane Company and the French Sud Aviation were working on projects called Type 233 and SuperCaravelle, respectively. Both projects were largely financially supported by those governments. The British project had a thin, deltoid-wing design (largely due to Dietrich Küchemann's contribution) for a transatlantic aircraft of about 100 passengers, while the French intended to build an aircraft with medium range.

Both projects were ready to enter the prototype phase in the early 1960s, but the costs were so high that the British government made it a condition for the BAC to find international co-operation. Proposals have been made to certain countries, but only France has shown real interest. The development project was negotiated as an international treaty between two countries rather than as a trade contract between 2 companies and included a clause, initially requested by the UK, which provided for significant penalties in case of a waiver. 
The treaty was signed on November 28, 1962 Meanwhile, the two companies merged into new ones; thus the Concorde project was signed between British Aircraft Corp., and Aerospace.

At first, the new consortium intended to produce two versions of the aircraft, one for long distances and one for short distances. However, potential customers did not show interest in the short-distance version and gave it up. The consortium secured orders for over 100 long-range aircraft from the most prestigious airlines of the moment: Pan Am, BOAC and Air France were the first customers, with six pieces each. Other airlines intending to order included Panair do Brasil, Continental Airlines, Japan Airlines, Lufthansa, American Airlines, United Airlines, Air Canada, Braniff, Singapore Airlines, Iran Air, Qantas, CAAC, Middle East Airlines and TWA.

Construction of the two prototypes began in February 1965: 001, built by Aerospatiale in Toulouse and 002, by BAC in Filton, Bristol. Concorde 001 made its first test flight from Toulouse on March 2, 1969 and reached supersonic speed on October 1. The first British Concorde flew from Filton Fairford Air Base on April 9, 1969, piloted by André Turcat. As the flight schedule evolved, 001 began a demonstration flight on September 4, 1971. Concorde 002 followed on June 2, 1972, with a flight to the Middle and the Far East. Concorde 002 made its first flight to the United States in 1973, landing in Dallas at the inauguration of Fort Worth Regional Airport.

These flights led to more than 70 orders for this aircraft, but a contest of circumstances led to their cancellation: The 1973 oil crisis, severe financial difficulties of many airlines, the spectacular crash in Paris at the Le Bourget air show, of Soviet competitor Tupolev Tu-144 and environmental issues such as sonic boom, takeoff noise and pollution. Only Air France and British Airways (BOAC's successor) kept their orders, with governments withholding profits. In the case of BA, $80 \%$ of the profit was withheld by the government until 1984, while the cost of purchasing the aircraft was covered by a state loan.

The United States discontinued its own Supersonic Transportation program (SST) in 1971. Two projects had entered the competition; the Lockheed L-2000, similar to the Concorde, lost to the Boeing 2707, which was to be faster, had a capacity of 300 passengers and had a design feature: A retractable wing. Other countries, such as India and Malaysia, have banned flying over Concorde supersonic flights due to noise issues.

Both airlines have been conducting test and demonstration flights since 1974. Testing of the Concorde aircraft set records that were not surpassed; the prototype, the pre-series and series aircraft covered 5,335 flight hours. A total of 2,000 test hours were performed at supersonic speeds. Costs per device were $£ 23$ million (\$ 46 million) in 1977. Development costs were six times higher than estimated (Antonescu and Petrescu, 1985; 1989; Antonescu et al., 1985a; 1985b; 1986; 1987; 1988; 1994; 1997; 2000a; 2000b; 2001; Aversa et al., 2017a; 2017b; 2017c; 2017d; 2016a; 2016b; 2016c; 2016d; Brewer, 1991; Cao et al., 2013; Dong et al., 2013; Franklin, 1930; He et al., 2013; 2008; Langston, 2015; 2016; Lee, 2013; Lin et al., 2013; Liu et al., 2013; Padula and Perdereau, 2013; Perumaal and Jawahar, 2013; Petrescu, 2011; 2012; 2019a-i; 2020; Petrescu and Petrescu, 2019a-c; 1995a-b; 1997a-c; 2000a-b; 2002a-b; 2003; 2005a-e; 2011 a-c; 2012 a-b; 2013 a-e; 2014 a-h; 2016a-c; 2020; Petrescu et al., 2007; 2009; 2016; 2017a-y; 2018a-p; 2020; Petrescu and Calautit, 2016a-b; Svensson et al., 2004; Rahman, 2018; Kisabo et al., 2019a-b; Kisabo and Adebimpe, 2019; Kosambe, 2019a-d; Sharma and Kosambe, 2020; Oni and Jha, 2019; Chaudhary and Kumar, 2019; de Lima et al., 2019; Babu et al., 2019; 2020; de Mota Siqueira et al., 2020; Tumino, 2020; Mishra, 2020a-b; Brischetto and Torre, 2020).

\section{Materials and Methods}

The Concorde was a delta (or "warhead") winged aircraft with four Olympus engines based on those originally developed for the strategic Avro Vulcan bomber. The engines were built in cooperation by RollsRoyce and SNECMA. Concorde was the first civilian aircraft with fully electric flight control circuits. The plane's muzzle was tilted for better visibility at low speeds and increased aerodynamics at high speeds.

These and other features allowed the Concorde to reach an average cruising speed of Mach 2.02 (about $2,140 \mathrm{~km} / \mathrm{h}$ or $1,330 \mathrm{mph}$ ) with a maximum flight altitude of $18,300 \mathrm{~m}$, more than double the speed of conventional aircraft. The landing speed was relatively high: $298 \mathrm{~km} / \mathrm{h}$.

Concorde benefited from many technical innovations

For optimal, high-speed flight:

- Double delta-shaped wings (warhead)

- Engine air intake with variable section and electronic control

- Afterburner

- Electronically controlled motors, the predecessors of the current FADEC engine control system

- Tilt section of the muzzle for increased visibility on landing

For low weight and high performance:

- Cruising speed of Mach 2.04 (2,200 km/h) for optimum fuel consumption (minimum supersonic resistance) 
- Aluminum alloy fuselage and wings, a good compromise between weight and temperature resistance

- Autopilot that allowed automatic power management and hands-free operation of the aircraft from takeoff to landing

- All-electric fly-by-wire control circuits

- Multifunctional flight control surfaces

- High-pressure hydraulic system (28 MPa) for lighter hydraulic components

- Electrical control of the braking system

- Stabilization of the aircraft by internal transfer of fuel inside the fuselage, thus controlling the center of gravity

- One-piece molded components for reducing joints and weight

- Lack of an auxiliary generator (Concorde will operate only on large airports, equipped with ground generators)

The main benefit of the Concorde program was the experience gained in design and manufacturing which later became the foundation of the Airbus consortium. Snecma Moteurs' involvement in the Concorde program prepared the company's debut in engine design and production for the civilian sector, opening up international cooperation with General Electric and the production of the successful CFM56 series of engines.

Although Concorde was at the height of the technique when it was introduced in 1970, 30 years later, its cockpit, full of classical instruments and buttons, now seems obsolete. With no competitors, there was no pressure to upgrade the Concorde with improved equipment and cabin comfort, as was the case with other older models, such as the Boeing 747.

The key partners, BAC (later BAE Systems) and Aerospatiale (later EADS) were the co-owners of the certificate for the Concorde model. The responsibility for this certificate was transferred to Airbus with the formation of Airbus SAS.

Many of the problems were overcome during the research and development of the Concorde project.

During the flight, the fuel was moved to optimally position the center of gravity relative to the center of pressure at a certain phase of the flight: At subsonic speeds in front, at supersonic speeds in the rear. The shape of the wings was designed to reduce the effect of this change in forces.

Concorde is a four-engine aircraft. The engines are arranged in pairs.

A major problem with the design and construction of the engines arose from the fact that the plane flew at both subsonic and supersonic speeds, while the speed of the air passing through the engine had to be lower than that of sound, even at supersonic speeds. The construction solution included a pair of intake ramps and a series of flaps whose position was changed during the flight to close or open them. The ramps were located in front of the engine compartment. At take-off, when the engine was fully loaded, the ramp section was fully open and an additional flap was opened to allow maximum airflow. As the aircraft approached a speed of 0.7 Mach, this additional flap was closed; at 1.3 Mach the inlet section began to be blocked to deflect airflow to pressurize the cab and cool the engine housing. At Mach 2.0, half of the intake ramp section was blocked. Their effect was twofold: They compressed and heated the air that reached the engine.

Stopping an engine on conventional aircraft is a big problem; the aircraft loses its propulsive force and the engine resists forward and drifts, bending in the direction of the defective engine. If this had happened in the case of the Concorde aircraft at supersonic speeds, the resistance structure of the aircraft would have failed. However, a stopped engine no longer needs air, so in the case of the Concorde aircraft, the effects of stopping an engine were immediately counterbalanced by opening the additional shutter and completely closing the intake ramps, diverting air around the engine, gaining lift and minimizing resistance. defective engine aerodynamics. During the tests with the Concorde aircraft, both engines on the same side of the aircraft could be stopped at Mach 2 speed without any difficulty in controlling the aircraft.

The engine of the English Vulcan bomber, Bristol (then Rolls-Royce plc) OLYMPUS 593 was the basis of the one that equipped the Concorde plane. Significant changes have allowed increased traction and decreased subsonic consumption. The final version was Mk IV. The (difficult) design, construction and tuning of the air routes upstream and downstream of the engine were carried out by SNECMA. (moving parts, ramps, etc.). The French Concorde aircraft were equipped with the same engines as the English ones, only they were assembled by SNECMA.

Engine section: Single flow, double body (low and high-pressure compressor), annular combustion chambers, low and high-pressure turbines. A postcombustion system and a variable section flue gas exhaust system have been added. An accessory coupling, driven by the high-pressure body, allowed the operation of alternators, hydraulic pumps, low and high-pressure fuel pumps. Power adjustment is performed in the highpressure body (unlike current motors where the adjustment is made in the low-pressure body).

The plane used afterburn only to take off and switch to supersonic mode. The engines were able to reach speed 2 Mach and without afterburning, but in practice, it was found that the plane consumed much more fuel during the trans-sonic period, even if the afterburning is relatively inefficient. Because jet engines are not at all 
efficient at low speeds, the Concorde ran on the track using only two engines running.

Rubbing the outer surfaces with air led to the cabin heating during the flight. Interior surfaces, such as windows or panels, were warm to the touch at the end of the flight. Except for the engines, the hottest structure of a supersonic aircraft is the muzzle. Engineers used Hiduminium R.R. 58, an aluminum alloy for the entire aircraft, due to the low cost and ease of processing. The maximum temperature supported by aluminum during the life of the aircraft was $127^{\circ} \mathrm{C}$, limiting the maximum speed to Mach 2.02 .

During the flight, Concorde went through two cycles of heating and cooling, first cooling as the altitude increased and then warming up during the supersonic flight. The reverse happened when going down and slowing down. Due to the heat generated by the compression of the air in supersonic mode, the fuselage of the Concorde aircraft expanded by about $300 \mathrm{~mm}$, the visible effect of this was a free space that appeared in the cockpit between the flight engine desk and the wall. On all the planes that were withdrawn, the flight engineers put their caps in that space before it cooled down, where they have remained until today.

To cool the cabin, the fuel was used as a heat exchanger. The hydraulic fluid was cooled in the same way. During the supersonic flight, the cabin windows warmed up strongly.

Due to the relatively high speed of about $400 \mathrm{~km} / \mathrm{h}$, the Concorde needed excellent brakes. Concorde used an anti-lock system, which prevented the wheels from locking when a maximum braking force was applied, allowing maximum deceleration and control during braking, especially in rainy conditions. The brake discs were made of ceramic and it took $1600 \mathrm{~m}$ to stop the 185-ton plane from a landing speed of $305 \mathrm{~km} / \mathrm{h}$. The discs were heated during the braking maneuver to temperatures between $300^{\circ} \mathrm{C}$ and $500^{\circ} \mathrm{C}$, needing a few hours to cool and fans were installed that accelerated their cooling. A temperature probe was mounted on each disc to monitor the temperatures of the brake discs.

Another problem encountered during the design was the landing gear. It had to be quite durable due to the exceptional loads the plane was subjected to during takeoff. Each main train had four wheels. The tires were inflated with nitrogen to limit overheating. After the 1979 incident in Washington, a tire pressure detection system was installed and an alarm signal from the system requires the plane to return from the road for checks.

Concorde had to travel the distance between London and New York or Washington without a stopover, so the plane was designed to be a supersonic plane with the greatest autonomy. The aim was to carefully design the engines for maximum efficiency at supersonic speeds, the shape of the wings for increased load capacity and minimum resistance, minimizing weight and payload, increasing fuel capacity and moving it to stabilize the aircraft without the need to use additional external devices.

However, shortly after the launch of the Concorde aircraft, the Concorde "B" was designed with a slightly increased fuel capacity, with enlarged wings provided with flaps on the attack board to improve aerodynamic performance at all speeds and more powerful engines with noise attenuators and without afterburner system. The result was an increased range of $500 \mathrm{~km}$ at a higher payload and the opening of new trade routes. The project was canceled due to poor sales of the first Concorde model.

The high altitude at which Concorde flew exposed passengers to a double stream of ionizing radiation compared to passengers on conventional routes. However, due to the short flight time, the total dose received was lower over the same distance. The unusual solar activity led to an increased incidence of radiation, so there was a radiometer and an instrument onboard that measured the rate of radiation decrease. If the level was too high, the aircraft would fall below $14,000 \mathrm{~m}$. The rate of decrease indicated by the instrument indicates whether the aircraft should descend further, reducing the flight time to unsafe altitude.

The cockpit of an aircraft normally starts to be pressurized at an altitude of between 1,800 and 2,400 and as the aircraft gains altitude. Pressurization of the Concorde began around $1,800 \mathrm{~m}$. Some passengers may have problems even at that level of pressurization. A sudden change in cabin pressure is dangerous for passengers and crew. The maximum cruising altitude of the Concorde aircraft was $18,000 \mathrm{~m}$, although the typical altitude reached during the London-New York distance was $17,000 \mathrm{~m}$; conventional airliners reach a cruising altitude below $12,000 \mathrm{~m}$. Above $15,000 \mathrm{~m}$, lack of oxygen leads to loss of consciousness, even for an athlete, in about 10-15 sec. At the altitude at which the Concorde aircraft flew, the air density is very low; any cracking of the fuselage would lead to such severe depressurization that the oxygen masks would have been useless, the passengers immediately entering a state of hypoxia even with the masks on. Therefore, the windows of the Concorde aircraft were smaller to avoid very rapid depressurization in the event of a crack. In addition, there was an additional air supply and the aircraft was immediately lowered to a safe altitude. The pilots had access to special masks that forced the ventilation of the lungs with oxygen under pressure (CPAP system).

The tilting muzzle of the Concorde aircraft, developed by Marshall Aerospace, allowed the aircraft to have an aerodynamic shape at cruising speed, but not to obstruct the pilot's field of vision during runway, take-off and landing maneuvers. Due to the large angle of attack, the 
elongated snout obstructed visibility and therefore had to be tilted. The tilting snout also included a movable visor, retractable inside the snout before it descended. When the muzzle was raised, the visor also rose in front of the cab window for aerodynamic efficiency.

A control module in the cab allowed the visor to retract and the muzzle to lower by $5^{\circ}$ from the standard horizontal position during runway and take-off. After the plane took off and took off from the airport, the muzzle and visor rose. Before landing, the visor retracted and the muzzle lowered to $12.5^{\circ}$ below the horizontal for increased visibility. After landing, the muzzle returned to the five-degree position to reduce the risk of damage.

The Federal Aviation Administration has objected to the poor visibility of the visor used on the first two Concorde prototypes, requiring the tilt muzzle solution to allow the Administration to allow Concorde aircraft to operate at the US airports. This led to the restoration of the visor used on production aircraft and the four preproduction aircraft (101, 102, 201 and 202). The front window and the visor glass, which had to withstand temperatures above $100^{\circ} \mathrm{C}\left(212^{\circ} \mathrm{F}\right)$ at supersonic speed, were built by Triplex.

In 1981 in the United Kingdom, the future of the Concorde was bleak. The government had lost money annually from operating the Concorde aircraft and operations were on the verge of being halted. Although a plan to reduce the cost of flight tests was presented, the government did not want to continue the project, losing so many years. In late 1983, British Airways CEO Sir John King persuaded the government to sell the aircraft to the airline (then, state-owned and then privatized) for $£ 16.5$ million-plus first-year profit.

A market study found that target passengers believed that a Concorde flight was more expensive than it actually was. As a result, British Airways increased prices progressively to support these perceptions, with the company reporting profits, unlike the French company.

While commercial planes took $7 \mathrm{~h}$ to fly from New York to Paris, the average supersonic flight time on transatlantic routes was less than 3.5 h. Until 2003, Air France and British Airways operated daily flights to New York. Concorde also flew to the Barbados Islands during the winter holidays. Until the Paris crash ended virtually all charter flights for both Air France and British Airways, several British and French tour operators operated numerous regular charter flights to many European destinations. In 1985, a British Airways Concorde plane landed at Cleveland Hopkins International Airport, accelerating the modernization of the airport and its transformation into an international one in 2000, Concorde was to return to Cleveland, but due to the Paris accident, this flight did not it took place before. The 1985 flight took $3 \mathrm{~h}$ and $10 \mathrm{~min}$ from Cleveland to London. Between Cleveland and New
York, the plane flew at subsonic speed, thus increasing the travel time. They wanted to operate a flight to Cleveland, but due to the fact that the airport was close to a residential area, the plan was not carried out.

Between October 12 and 13, 1992, to commemorate the 500th anniversary of Columbus' landing in the New World, the American company Concorde Spirit Tours organized a flight with the Concorde - Air France aircraft around the world in $32 \mathrm{~h} 49 \mathrm{~min}$ and $3 \mathrm{sec}$, departing from Lisbon, Portugal, including 6 power stops in Santo Domingo, Acapulco, Honolulu, Guam, Bangkok and Bahrain.

The speed record to the East was set by the same Concorde of Air France in the charter flight of Concorde Spirit Tours (USA), on August 15-16, 1995. This promotional flight circled Earth from New York/JFK International Airport in 31 h. $27 \mathrm{~min} 49 \mathrm{sec}$, including 6 stops for refueling in Toulouse, Dubai, Bangkok andersen AFB (Guam), Honolulu and Acapulco. Concorde still holds this record.

In 1977, British Airways and Singapore Airlines used a Concorde plane for flights between London and Singapore via Bahrain. The aircraft bore the insignia of both Singapore Airlines and British Airways. The flights were interrupted after only 3 flights due to complaints from the Malaysian government about the noise produced; flights could not be resumed until a route was bypassed around Malaysia in 1979. A dispute with India prevented supersonic speeds from being reached in Indian airspace and the route was declared unviable and stopped in 1980. Air France operated with Concorde 2 weekly flights to Mexico City via Washington, DC or New York City, from September 1978 to November 1982. The global economic crisis of that period led to the closure of these routes, the last flights being almost empty. The route between Washington or New York and Mexico City included a deceleration from 2.02 to 0.95 Mach, to avoid the sonic boom over the state of Florida, followed by an acceleration to 2.02 Mach over the Gulf of Mexico. Air France could have avoided this maneuver by flying between Miami and Bimini, with the Bahamas bypassing Key West, Florida. British Airway, however, implemented this route on April 1, 1989, during a luxury cruise around the world. Concorde also flew to Mexico City and Acapulco on various charter flights.

Between 1984 and 1991, British Airways operated 3 Concorde flights a week between London and Miami, with a stopover in Washington. The journey between Washington and Miami was made with subsonic speed to the point of Carolina Beach; then followed rapid access to $18,000 \mathrm{~m}$ (about $1,800 \mathrm{~m}$ per minute) thanks to the low weight of the aircraft: About 25-30 passengers and fuel only for the Washington - Miami sector. After 6-8 min at 2.02 Mach, the deceleration and descent to Miami began. Sometimes, due to the bad weather in 
Washington and the low load on leaving Miami, the Miami-London sector was non-stop. Thus, the fastest flight lasted $3 \mathrm{~h}$ and $47 \mathrm{~min}$, covering a distance of 4000 nautical miles $(7,400 \mathrm{~km})$ between Miami and London, with 70 passengers on board. In such cases, the stop was in Shannon, Ireland, with the re-authorization of the flight to London depending on the amount of fuel remaining available. This flight was longer than the special Washington-Nice flight, which was said to be the longest non-stop flight to Concorde.

Between 1978 and 1980, Braniff International Airways leased 10 Concorde aircraft, 5 from Air France and 5 from British Airways. They were used for subsonic flights between Dallas and Washington, operated by Braniff airline crews, then taken over by Air France and British Airways crews for supersonic flights to London and Paris. The aircraft was registered in the United States but also in their countries of origin: A sticker-covered European registration number when operated by Braniff. The races were unprofitable and less than $50 \%$ occupied, forcing Braniff to relinquish Concorde's sole U.S. operator status in May 1980.

The experience aboard the Concorde aircraft was much different from that experienced onboard subsonic commercial aircraft. Air France and British Airways have arranged the passenger cabin in a single class with 100 seats - four transverse seats with a corridor in the center. The maximum height of the central aisle was 1.8 $\mathrm{m}$ and the leather seats were unusually narrow. The seats were $97 \mathrm{~cm}$ high with a little more legroom than a standard economy class seat. Due to the limited space, hand luggage was very limited.

At the level of the 1990s, equipment specific to the luxury or business class typical of long-haul aircraft such as Boeing 747, video monitors, rotating, or reclining seats, were absent at Concorde. However, the flight time between London and New York - about 3 and a half hours - made up for these shortcomings. There is a plasma display in front of the cab that indicates altitude, air temperature and current speed in miles per hour as well as Mach numbers. (Air France had a single display that indicated only speed in Mach numbers.)

To compensate for the lack of comfort, the on-board service was at the highest standards. Passengers were offered free champagne and selected food served with miniature silverware.

The experience of crossing the sound barrier was accompanied by a short sustained acceleration and was announced by one of the pilots.

Flying at double altitude compared to a conventional aircraft, the curvature of the Earth could be clearly seen through the windows and turbulence was rare. During the supersonic flight, although the outside temperature was $-60^{\circ} \mathrm{C}$, the compression of the air warmed the outer shell in front of the aircraft to about $+120^{\circ} \mathrm{C}$, making the windows warm to the touch and causing a noticeable increase in ambient temperature throughout the cabin.

The delta-shaped wings allowed the Concorde to obtain a higher angle of attack than a conventional aircraft, causing the formation of large low-pressure vortices on the entire upper surface of the wing, creating lift. This low pressure caused the plane to disappear into a veil of fog on days with high humidity. The vortices formed only at low speeds, during ascent or descent, the aircraft then experiencing slight turbulence. Concorde flew fast enough so that the weight of the passengers was temporarily reduced by $1 \%$ when flying east. This was due to the centrifugal force resulting from the cumulation of the Earth's speed and rotation speed. Flying west, the weight increased by $0.3 \%$ as it canceled out the normal rotation and, with it, the normal centrifugal force and replaced it with a smaller rotation in the opposite direction. Also, the weight of those on board was reduced by another $0.6 \%$ due to the distance from the center of the Earth.

The speed of the Concorde exceeded that of twilight and could equal or exceed the speed of the earth's rotation. On westbound flights, it was possible to arrive at a local time earlier than the departure time. On some transatlantic flights departing from Heathrow or Paris, you could take off right after sunset and catch up, landing during the day. This was well publicized by British Airways, which used the slogan "Arrive before you leave."

A very important feature was its maneuverability. Concorde had the characteristics of a fighter jet that could decelerate very quickly from Mach 1.9 to Mach 0.7 in $20 \mathrm{sec}$. Concorde was so flexible that in extreme cases he could avoid avoidance.

On July 25, 2000, Air France 4590 flight, registered F-BTSC, crashed in Gonesse, France, killing all 100 passengers, 9 crew members and 4 people on the ground. It was the only accident with victims of this type of plane. According to the official investigation conducted by the French Accident Investigation Bureau (BEA), the accident was caused by a titanium blade, part of a power inverter, which fell from the DC-10 plane of Continental Airlines that took off about $4 \mathrm{~m}$ before. This metal fragment caused an explosion of a left landing gear tire. A piece of exploded rubber hit the fuel tank and broke an electric cable. The impact caused a hydrodynamic shock wave that cracked the tank near the impact area. This crack caused a massive loss of fuel that ignited from the damaged cables that produced sparks. The crew stopped engine number 2 following the fire alarm but were unable to lift the landing gear, making it difficult for the aircraft to ascend. Powerless, the plane crashed and crashed into a hotel in Gonesse.

The BEA report was challenged, citing evidence that the Concorde had been overloaded, fuel was not evenly 
distributed and that the landing gear was missing a vital component. It was concluded that the aircraft deviated from its normal course from the runway, which reduced the take-off speed below the minimum critical value. Prior to this accident, Concorde was the safest commercial aircraft in operation in terms of casualties per kilometer, i.e., zero. However, the safety of an aircraft cannot be accurately measured from a single incident. The crash of the Concorde plane belonging to Air France meant the beginning of the end of this exceptional type of plane, leaving all kinds of opinions and impressions, maybe even possible sabotage on the best plane so far in human history.

The accident resulted in a number of changes, including better electrical insulation, Kevlar reinforcements to the fuel tanks and special explosion-proof tires.

\section{Results and Discussion}

Aviation record: How short was the fastest flight between New York and London? British Airways managed to break the record for the fastest flight between New York and London. The flight between the two big cities managed to break a record set in 2018 when it reached from one point to another in just four hours and 56 min. The aircraft used was a Boeing 747, which managed to reach an exceptional speed of 1,327 kilometers per hour, according to Flightradar24, an online service that monitors flights.

However, the record is not necessarily based on any technological developments in terms of aircraft or the development of any complicated system that would help set the record for the fastest subsonic flight between the two cities. The reason would have been storm Ciara, which would have contributed to the propulsion of the plane. The gusts of wind, which blew on Saturday night to Sunday at a speed of about $320 \mathrm{~km} / \mathrm{h}$ helped to increase the speed of the plane and reduce the flight time.

On the other hand, the planes that traveled in the opposite direction that night lasted about two and a half hours more due to the wind.

The plane took off from JFK Airport in New York and landed at Heathrow Airport in London for almost two hours faster than scheduled, after four hours and 56 min. According to Flightradar24, this flight between New York and London takes an average of six hours and 13 min. These are subsonic flights, in which aircraft move at a high speed but lower than the speed of sound.

British Airways broke the 2018 record for the fastest flight between the two cities of the Norwegian company. Then a plane that flew from New York to London reached its destination in five hours and $13 \mathrm{~min}$.

However, storm Ciara "helped" other flights on Saturday night to Sunday. The British Airways flight was only a minute faster than a Virgin Atlantic flight with an Airbus A350, which landed just moments after BA.
It seems that there is a race between all the big passenger companies that want to finish their flights a little better and faster than they would have planned.

Obviously, if such aspects become important, the fight between the big companies producing commercial ships in the refurbishment and design of devices capable of increasing the speed of their ships built by them is sharpened.

One tries to combine different requirements and engineering optimizations to take into account as many of the new requirements: Flight quality, flight and passenger safety, increased flying speeds, fuel economy, switching to other renewable and sustainable fuels or hybrid models, higher power, increased comfort for passengers and pilots, cheaper flights overall.

The materials used must meet several requirements simultaneously with high strength, high elasticity, absorption power, but be light and reliable.

In other words, we might think that if a storm moved ships in flight much faster when they were in the direction of the cyclone and on the contrary, ships flying against the cyclone were much delayed, perhaps it will be possible to use the force of nature in the future to move faster. This would mean that today with very precise data on what the weather will be like on the globe, certain flights could be scheduled to take place in the direction of the current of some cyclones and not against them.

On the other hand, ships capable of flying at very high altitudes are already being designed, ships that go into outer space and then move in Earth orbits, where there is more space, less traffic and no storms and the resistance of air (rarefied or totally missing) is insignificant.

A flight of this kind through outer space is much more desirable, where the influence of storms no longer exists than to try to correlate our flight with atmospheric cyclones, even if outside the Earth's atmosphere we need oxygen in the cockpits and for passengers because anyway the modern flight takes place for a long time at high altitudes where the air is thinner anyway but storms and cyclones still meet.

Thus, it would be more useful, for example, to distort the space in which we live in the spacecraft area (as Einstein proposed) to cause it to push us forward with fantastic speeds (an SF idea but which could already be considered by the science' humans today).

Supersonic travel is a speed of movement of an object that exceeds the speed of sound (Mach 1). For objects traveling in dry air at a temperature of $20^{\circ} \mathrm{C}$ $\left(68^{\circ} \mathrm{F}\right)$ at sea level, this speed is approximately $343.2 \mathrm{~m} / \mathrm{s}$ $(1,126 \mathrm{ft} / \mathrm{s} ; 768 \mathrm{mph} ; 667.1 \mathrm{kn} ; 1,236 \mathrm{~km} / \mathrm{h})$. The speed five times faster than the speed of sound (Mach 5) is often called hypersonic. Flights during which only parts of the air surrounding an object, such as the ends of the rotor blades, reach supersonic speeds are called transonic. This usually occurs somewhere between Mach 0.8 and Mach 1.2. 
Sounds circulate vibrations in the form of pressure waves in an elastic medium. In gases, sound circulates longitudinally at different speeds, largely depending on the molecular weight and temperature of the gas and the pressure has a reduced effect. Because the temperature and air composition vary significantly with altitude, Mach numbers for aircraft can change despite a constant speed of movement. In-room temperature water, supersonic velocity can be considered as any velocity greater than $1,440 \mathrm{~m} / \mathrm{s}(4,724 \mathrm{ft} / \mathrm{s})$. In solids, sound waves can be polarized longitudinally or transversely and have even higher speeds.

Supersonic fracture is a faster crack movement than the speed of sound in a fragile material.

In the early twentieth century, the term "supersonic" was used as an adjective to describe sound whose frequency is beyond the limits of normal human hearing. The modern term for this is "ultrasonic".

The tip of a bullwhip is thought to be the first manmade object to break the sound barrier, leading to a "crack" (actually a small sonic boom). The movement of the wave traveling through the bull is what makes it able to reach supersonic speeds.

Most modern fighter jets are supersonic aircraft, but there were supersonic passenger aircraft, namely the Concorde and Tupolev Tu-144. Both passenger planes and some modern fighter jets are also capable of overlapping, a sustained supersonic flight condition without the use of fuel. Due to its multi-hour overload capability and relatively high flight frequency over several decades, Concorde spent more time flying supersonically than all other aircraft combined with a considerable margin. Since the final Concorde withdrawal flight on 26 November 2003, supersonic passenger aircraft have not operated. Some large bombers, such as the Tupolev Tu-160 and the Rockwell B-1 Lancer, are also capable of supersonic velocities.

Most modern bullets with firearms are supersonic, projectiles with rifles often move at close range and, in some cases, far exceed Mach 3.

Most spacecraft, especially those of the spacecraft, are supersonic at least during re-entry portions, although the effects on the spacecraft are reduced by low air densities. During the ascent, launch vehicles generally avoid supersonic passage below $30 \mathrm{~km}(\sim 98400 \mathrm{~m})$ to reduce air traction.

Note that the speed of sound decreases somewhat with altitude, due to lower temperatures there (usually up to $25 \mathrm{~km}$ ). At even higher altitudes the temperature begins to rise, with the corresponding increase in the speed of sound.

When an inflated balloon bursts, the broken pieces of latex contract at supersonic speed, which contributes to the loud and loud noise.
So far, only one land vehicle has officially traveled at supersonic speed. It is ThrustSSC, driven by Andy Green, which holds the world record for ground speed, achieving an average speed on the two-way race of $1,228 \mathrm{~km} / \mathrm{h}(763 \mathrm{mph})$ in the Black Rock Desert of October 15, 1997.

The Bloodhound LSR project is planning an iconic 2020 test at Hakskeen Pan in South Africa with a combined jet and a hybrid rocket machine. The goal is to break the existing record, then make other attempts during which the team hopes to reach speeds of up to $1,600 \mathrm{~km} / \mathrm{h}(1,000 \mathrm{mph})$. The effort was initially led by Richard Noble, who was the leader of the ThrustSSC project, however, following funding issues in 2018, the team was bought by Ian Warhurst and renamed Bloodhound LSR. The new project retains many of Bloodhound SSC's original engineering staff and Andy Green is still the record test engine, with high-speed testing set to begin in October 2019.

Supersonic aerodynamics are simpler than subsonic aerodynamics because air sheets at different points along the plane cannot affect each other. Supersonic jets and rocket vehicles require several times more traction to fire through the additional aerodynamic traction experienced in the transonic region (around Mach 0.85-1.2). At these speeds, aerospace engineers can easily guide the air around the aircraft's fuselage without producing new shock waves, but any change in the transverse area away from the vehicle leads to shock waves throughout the body. Designers use the supersonic surface rule and the Whitcomb area rule to minimize sudden changes in size.

However, in practical applications, a supersonic aircraft must function stably in both subsonic and supersonic profiles, so that the aerodynamic design is more complex.

One problem with sustained supersonic flight is the generation of heat in flight. Aerodynamic heating can take place at high speeds, so an aircraft must be designed to operate and operate at very high temperatures. Duralumin, the traditional aircraft material, begins to lose strength and go into plastic deformation at relatively low temperatures and is not suitable for continuous use at speeds above Mach 2.2 to 2.4. Materials such as titanium and stainless steel allow operation at much higher temperatures. For example, the Lockheed SR-71 Blackbird jet could fly continuously at Mach 3.1, which could cause temperatures in some parts of the aircraft to exceed $315^{\circ} \mathrm{C}\left(600^{\circ} \mathrm{F}\right)$.

Another area of concern for high speed sustained flight is engine operation. Jet engines create impulses by increasing the temperature of the air they ingest and as the aircraft accelerates, the intake compression process causes the temperature to rise before it reaches the engines. The maximum allowable exhaust temperature is determined by the turbine materials behind the engine so 
that as the aircraft accelerates, the difference in intake and exhaust temperature that the engine can create by burning fuel also decreases. The press. The higher throw required for supersonic speeds had to be found by burning the extra fuel in the exhaust. The admission project was also a major issue. Much of the energy available in the intake air must be recovered, known as the intake manifold, using shock waves in the process of supersonic compression in the intake. At supersonic speeds, the intake must ensure that, when the air slows down, it does so without excessive pressure loss. It must use the correct type of shock wave, oblique/airplane so that the design speed of the aircraft compresses and slows down the air at subsonic speed before it reaches the engine. Shock waves are positioned using a frame or cone that may need to be adjusted according to the trade-offs between complexity and required aircraft performance.

An aircraft capable of operating at supersonic speeds for a long time has a potential advantage over a similar project that operates subsonically. Most photos that an aircraft observes as it accelerates at supersonic speeds take place just below the speed of sound, due to an aerodynamic effect known as wave traction. An aircraft that can accelerate above this speed sees a significant decrease in traction and can fly supersonically with improved fuel economy. However, due to the way the elevator is generated in a supersonic mode, the traction ratio of the aircraft as a whole decreases, which leads to a shorter interval, compensating for or reversing this advantage. The key to having low supersonic traction is the correct modeling of the general aircraft to be long and thin and close to a "perfect" shape, the von Karman headlights or the Sears-Haack body. This has led to almost all supersonic cruise aircraft that look very similar to each other, with a very long and slender fuselage and large delta wings, cf. SR-71, Concorde, etc. Although not ideal for passenger aircraft, this modeling is quite adaptable for the use of bombers.

Aviation research during World War II led to the creation of the first missile and jet aircraft. Subsequently, there were several claims to break the sound barrier during the war. However, the first recognized flight that exceeded the speed of sound by an aircraft equipped in a controlled flight was performed on October 14, 1947, by the Bell X-1 research missile piloted by Charles "Chuck" Yeager. The first production plane to break the sound barrier was an F-86 Canadair Saber, with the first "supersonic" female pilot, Jacqueline Cochran, in control. According to David Masters, the DFS 346 prototype captured in Germany by the Soviets, after being released by a B-29 at $100800 \mathrm{~m}(3200 \mathrm{ft})$, reached $1100 \mathrm{~km} / \mathrm{h}$ at $683 \mathrm{mph}$ at the end of 1945, which was to be overcome. Mach. 1 at that height. The pilot in these flights was the German Wolfgang Ziese. On August 21, 1961, a Douglas DC-8-43 (registration N9604Z) overtook Mach 1 in a controlled dive during a test flight at Edwards Air Force Base. The crew was William Magruder (pilot), Paul Patten (co-pilot), Joseph Tomich (flight engineer) and Richard H. Edwards (flight test engineer). This was the first supersonic flight of a civilian aircraft other than the Concorde or Tu-144.

A single accident to the fastest, safest and best aircraft in human history has led to its decommissioning and the slowdown of Mach programs. However, after a certain period, these supersonic programs were resumed all over the world because the need for modern, fast flights was growing, the requirements were also more pressing.

Skylon is a series of projects for a spacecraft in orbit by the British company Reaction Engines Limited (REL), using SABER, a combined cycle air-to-air missile propulsion system. The design of the vehicle is for a hydrogen-based aircraft that would take off from a specially built runway and accelerate to Mach 5.4 at 26 $\mathrm{km}(85,000 \mathrm{ft})$ altitude (compared to typical $9-13 \mathrm{~km}$ airlines) using oxygen. atmospheric before starting the engines to use the internal Liquid Oxygen source (LOX) to take it into orbit. It could carry 17 tons $(37,000 \mathrm{lb})$ of cargo in the Earth's low equatorial orbit (LEO); up to 11 tons $(24,000 \mathrm{lb})$ to the International Space Station, almost $45 \%$ more than the capacity of the European Space Agency's automatic transfer vehicle or 7.3 tons; 7,300 kilograms $(16,000 \mathrm{lbs})$ to the Geosynchronous Transfer Orbit (GTO), over $24 \%$ more than the reusable SpaceX Falcon 9 launch vehicle in 2018. The relatively light vehicle would then re-enter the atmosphere and land on a runway, being protected from the conditions of re-entry of a ceramic composite leather.

The Boeing F/A-18 Super Hornet is without a doubt the most sophisticated and capable multi-role fighter and ground attack aircraft in the United States Service today.

The Boeing F/A-18 Super Hornet has been controversial since the beginning, the new "terrible child" of the US Navy.

More than just an enlarged F/A-18C/D, the Super Hornet is a new aircraft characterized by a considerable improvement in its tactical capability. Appearing following the cancellation of the Grumman A-12 project and the rejection of the modernized Intruders and Tomcat models, Super Hornet generated both criticism and praise.

In the early 1990s, the United States Navy underwent a period of reconfiguration; not only because the disastrous Grumman A-12 Avenger II program was abandoned, but also because during the 1991 Gulf War, several shortcomings characteristic of the McDonnell Douglas F/A-18 Hornet were noted against Iraq. In 1992, the US Navy made the only possible decision: It went on to upgrade the Hornet fighter jet.

After the first flight in 1995, the Super Hornet aircraft was not bypassed by harsh criticism. The US Navy 
command remained firmly in place and the result was above expectations, the ratings of $\mathrm{F} / \mathrm{A}-18 \mathrm{E} / \mathrm{F}$ being excellent. The load-bearing surface, wing span and stabilizers are $25 \%$ larger than the previous Hornet model. In addition, the air intakes have become larger to power the new turbojets, General Electric F414-GE400 , engines that have been designed to reduce the radar cross section. In reality, the reduction of the radar cross section was a great achievement in the redesign of the aircraft, so that the Super Hornet is provided with an absorbent coating of radar waves and carefully designed panels and slots, which keep the radar detection level to a minimum.

However, some of the most important improvements to the old Hornet are kept top secret. Since the first half of 2008, this aircraft has been equipped with 20 US Naval Forces operational squadrons; he is considered a true workhorse in the War on Terror.

An AESA APG-79 radar system (with active electronic scanning), located at the front of the aircraft, secretly tracks targets and guides missiles against multiple air-to-air threats. The aircraft also boasts an impressive IDECM integrated defensive electronic countermeasures electronic system, a Multifunctional Information Distribution System - MIDS, which transmits and receives data from countless sources, a cockpit in which an increased volume of data from electronic displays and weapons systems.

Since 2000, with the entry into operational service, the Super Hornet has constantly benefited from a whole series of upgrades to its on-board avionics that have increased its performance and operational potential.

The Lockheed SR-71 "Blackbird" is a long-range Mach 3+ strategic reconnaissance aircraft developed and manufactured by the American aerospace company Lockheed Corporation. It was operated by both the United States Air Force (USAF) and NASA. The SR-71 was developed as a black project from the Lockheed A12 reconnaissance aircraft in the 1960s by the Lockheed Skunk Works division. American aerospace engineer Clarence "Kelly" Johnson was responsible for many of the aircraft's innovative concepts. Form SR-71 was based on that of the A-12, which was one of the first aircraft designed with a reduced cross-section of the radar. At one point, a bomber variant of the aircraft was analyzed, before the program focused only on reconnaissance. Reconnaissance mission equipment includes signal information sensors, a side-view aerial radar and a camera; The SR-71 was both longer and heavier than the A-12, allowing it to hold more fuel, as well as a twoseater cockpit. The SR-71 designation was attributed to lobbying efforts by the head of the United States, Curtis LeMay, who preferred the designation Strategic Recognition (SR) to simple Recognition (RS). The aircraft was put into operation in January 1966.
During air reconnaissance missions, the SR-71 operated at high speeds and altitudes (Mach 3.2 and $85,000 \mathrm{~m}, 25,900 \mathrm{~m}$ ) to allow it to attack threats. If a surface-to-air missile launch was detected, the standard evasive action was simply to accelerate and ignite the rocket. On average, each SR-71 could fly once a week due to the extensive transformation required after mission recovery. A total of 32 aircraft were built; 12 were lost in accidents and none were lost in the action of the enemy. In 1988, the USAF withdrew the SR-71 largely for political reasons; several were briefly reactivated in the 1990s, before the second retirement in 1998. NASA was the final operator of this type, withdrawing its examples in 1999. Since retirement, the role of SR-71 has been taken over by a combination of satellites. reconnaissance and Unmanned Aerial Vehicles (UAVs); The proposed UAV successor, the SR-72, was developed by Lockheed Martin and scheduled to fly in 2025. The SR-71 received several nicknames, including "Blackbird" and "Habu". Since 2020, the SR-71 has continued to hold the world record set in 1976 for the fastest-breathing aircraft previously owned by the Lockheed YF-12.

Rockwell B-1 Lancer is a four-engine supersonic aircraft, variable geometry, heavy strategic bomber used by the United States Aviation (USAF). Following a competition in 1970, the B-1A developed by North American Rockwell was selected for the USAF program of a Mach 2 supersonic bomber with sufficient range and payload to replace the Boeing B- 52 Stratofortress and XB-70 (which was abandoned). It was later developed as the $\mathrm{B}-1 \mathrm{~B}$, primarily a low-level, long-range penetrator with Mach 1.25 speed (high-altitude speed capability), the low speed is due to changes in the air intakes of the engines to reduce the radar signature.

General Dynamics F-111 is a medium-range strategic bomber, reconnaissance aircraft and multi-role fighter aircraft, designed in the 1960s.

It introduced a number of technical innovations for series military aircraft: Variable geometry wings, afterburner turbofans and low-altitude ground tracking radar.

It is the forerunner of the iconic Grumman F-14 Tomcat and ranks 9th in the top of ultra-fast fighter jets. The F-111 reaches a speed of 2.5 Mach and the innovative design has been designed since 1960. It introduced a number of technical innovations for series military aircraft: Variable geometry wings, postcombustion turbofans and radar that allows identification with accuracy of objects on the ground.

The construction is what allows the aircraft to carry a weight of $13,600 \mathrm{~kg}$, which makes it indispensable in front battles.

The F-15 Eagle produced by McDonnell Douglas (Boeing, after joining in 1997) is a twin-engine postcombustion aircraft, capable of flying at night, in all 
weather conditions, designed to penetrate enemy airspace, to obtain and maintain air superiority. It was designed for the United States Air Force and flew for the first time in July 1972. It is one of the most representative aircraft of the modern era. Due to its unmatched performance and survivability, the F-15 will remain in active service and will be withdrawn in 2020 at the earliest.

The iconic "eagle" could have a long life, which will be extended to more than in 2025 . It has the same impressive speed as the F-111, of Mach 2.5, but it is a bit more graceful. It is produced by McDonnell Douglas (which is the current Boeing) and comes equipped with two afterburner engines, being able to fly in any weather conditions.

North American XB-70 "Valkyrie" was the prototype of a highly advanced strategic bomber, of high altitude and speed (Mach 3). The development of this aircraft worried the Soviet Union so much that it led to the creation of the MiG-25 Foxbat interceptor in response. The model was abandoned in 1962 because, unlike intercontinental ballistic missiles, the aircraft could no longer penetrate the Soviet anti-aircraft defense intended for the 1970s.

Valkyrie had duck-wings (duck) and main wings in a delta configuration. It was built mostly of stainless steel, honeycomb and titanium structure. It was designed to use a phenomenon called compression lift, which occurs when the shock wave generated by an aircraft at supersonic speeds is "trapped" under the wings, supporting some of the weight of the aircraft. Under the center of the wing, Valkyrie had a large partition at the center of the engine inlets, which was used to produce a strong shock wave. Acting on the wings, this shock allowed the plane to recover energy from its own trail left in the air. At high speeds, the compression lift increased the wing lift by up to $30 \%$, without any increase in forwarding resistance.

The outer portions of the wings were movable and could be tilted down by up to 65 degrees. This enhanced the directional stability of the aircraft at supersonic speeds, moved the lift center to a more favorable position at high speeds and strengthened the compression lift effect. With the tips of the wings lowered, the shock wave caused by the compression lift would be kept even more under control under the wings, instead of leaking beyond the tips of the wings.

The value of the maximum lift/forward resistance ratio at Mach 2.0 speed was approx. 6.0. In a similar flight mode, for B-58 Hustler the value was just under 5 and for Concorde of about 7.4.

XB-70 was the prototype of a strategic bomber, North American, very advanced and very high altitude. It could reach a speed of Mach 3, being much faster compared to the Mikoyan MiG-31 and American fighter planes such as the F-111 and F-15. For this reason, the construction of this aircraft worried the Soviet Union, which responded by creating the MiG-25 Foxbat interceptor.

These supersonic fighter jets did not have an active service, because too few prototypes were built, but the XB-70 Valkyrie was created with the idea of entering and leaving the battlefield as quickly as possible.

The first place in the top of supersonic fighter planes is given by Falcon HTV-2, which is an ultra-fast experimental vehicle that does not require a pilot. Developed as part of the Falcon DARPA project, it can reach impressive speeds of $20 \mathrm{Mach}$ and manages to beat all its competitors in terms of speed. HTV-2 was created for the purpose of collecting data and can cover a distance of 4.000 kilometers in less than $15 \mathrm{~min}$.

The first place in the top of supersonic fighter planes is given by Falcon HTV-2, which is an ultra-fast experimental vehicle that does not require a pilot. Developed as part of the Falcon DARPA project, it can reach impressive speeds of $20 \mathrm{Mach}$ and manages to beat all its competitors in terms of speed. HTV-2 was created for the purpose of collecting data and can cover a distance of 4.000 kilometers in less than $15 \mathrm{~min}$.

The US Department of Defense is planning a second test for its hypersonic aircraft, which can fly at an astonishing speed of $20,000 \mathrm{~km} / \mathrm{h}$, or 20 times the speed of sound (Mach 20).

If all goes according to plan, then the Pentagon, whose DARPA technology division, along with Lockheed Martin, is the aircraft maker, will be chosen with a lightning-fast military aircraft capable of launching an attack anywhere in the world in less than a year. hour. This type of ability is known as the Conventional Global Prompt Hit (CPGS).

To better understand the speed of Mach 20, a plane traveling in this mode can travel, for example, the distance between Bucharest and Madrid in about 6-7 min. The rocket will pierce the Earth's atmosphere, then release the Falcon HTV-2 into the suborbital region of the planet. The super-fast weapon will then descend over the Pacific Ocean at about $20,000 \mathrm{~km} / \mathrm{h}$.

The test flight will take $30 \mathrm{~min}$ before the HTV-2 lands and sinks at a distance of approximately 6,500 kilometers from Vandenberg Military Air Base. If the aircraft completes its mission, development projects will continue; otherwise, the program will be stopped indefinitely.

The first Falcon HTV-2 was launched in April 2010, but disappeared without a trace over the Pacific, after only nine minutes of flight and the vehicle was never recovered. The first flight was undertaken to improve aerodynamic models and to optimize the aspects of the second flight.

Being so fast, the first test of this type of plane failed miserably, due to the fact that the technique of that time could not follow it efficiently and especially the control. The plane simply disappeared without a 
trace and even today, after ten years, it is practically unknown what happened to it. Assumptions might be made, but what's the point? What is certain is that the plane reached the planned speed of Mach 20, after which it disappeared without a trace.

Virgin Galactic Space announced on Monday a preliminary partnership with engine maker Rolls Royce to develop an airliner that will be able to fly at three times the speed of sound;

Only the Concorde model, another supersonic aircraft, regularly carried passengers in the history of air transport from 1976 to 2003. Virgin Galactic wants to develop an aircraft that flies even faster (Mach 3 instead of Mach 2 for Concorde), but it will first have to solve the problems that led to the disappearance of the Concorde model from the market, mainly excessive noise and fuel consumption.

The aircraft imagined by Virgin Galactic, shown in several images on Monday, is a delta wing capable of accommodating between nine and 19 passengers, at an altitude of more than $18,000 \mathrm{~m}$ - about twice the altitude at which planes fly current line. The new aircraft will have to take off and land on the runways of existing airports.

Virgin Galactic has signed the protocol of a nonbinding agreement with Rolls Royce to develop the jet engine that will be mounted on the future aircraft model.

The mentioned company has so far focused only on the segment of flights operated within space tourism, thanks to a half-plane, half-rocket aircraft, designed to carry onboard six people, who float for a few minutes in conditions of weightlessness at the limit of the atmosphere with space. Several tests are yet to be conducted in the United States before the official launch of these commercial spaceflights.

Listed on the stock exchange last year, Virgin Galactic is trying to diversify and announced in May that it had signed an agreement with NASA to develop "highspeed" technologies.

The US space agency has been working for decades to develop a silent supersonic experimental aircraft, the X-59 and the first copy of this model is about to be built by Lockheed Martin in California. The goal is for the supersonic boom, the formidable explosion noise, caused by reaching the sound speed barrier, to become less noticeable - or not at all - on the ground.

The future of aviation sounds good now when it has already moved to Much 3, but for space rockets the speed already achieved is already much higher.

The development of high-speed aircraft will now go in parallel on at least two routes, one for aircraft flying by 2-3 Mach and will increase their speed in the future, they can already carry a large number of passengers and capable spacecraft of much higher speeds but which for the time being carries a limited number of passengers (cosmonauts).

\section{Conclusion}

Virgin Galactic Space announced on Monday a preliminary partnership with engine maker Rolls Royce to develop an airliner that will be able to fly at three times the speed of sound;

Only the Concorde model, another supersonic aircraft, regularly carried passengers in the history of air transport from 1976 to 2003. Virgin Galactic wants to develop an aircraft that flies even faster (Mach 3 instead of Mach 2 for Concorde), but it will first have to solve the problems that led to the disappearance of the Concorde model from the market, mainly excessive noise and fuel consumption.

The aircraft imagined by Virgin Galactic, shown in several images on Monday, is a delta wing capable of accommodating between nine and 19 passengers, at an altitude of more than $18,000 \mathrm{~m}$ - about twice the altitude at which planes fly current line. The new aircraft will have to take off and land on the runways of existing airports.

Virgin Galactic has signed the protocol of a nonbinding agreement with Rolls Royce to develop the jet engine that will be mounted on the future aircraft model.

The mentioned company has so far focused only on the segment of flights operated within space tourism, thanks to a half-plane, half-rocket aircraft, designed to carry onboard six people, who float for a few minutes in conditions of weightlessness at the limit of the atmosphere with space. Several tests are yet to be conducted in the United States before the official launch of these commercial spaceflights.

Listed on the stock exchange last year, Virgin Galactic is trying to diversify and announced in May that it had signed an agreement with NASA to develop "highspeed" technologies.

The US space agency has been working for decades to develop a silent supersonic experimental aircraft, the X-59 and the first copy of this model is about to be built by Lockheed Martin in California. The goal is for the supersonic boom, the formidable explosion noise, caused by reaching the sound speed barrier, to become less noticeable - or not at all - on the ground.

\section{Acknowledgement}

This text was acknowledged and appreciated by Dr. Veturia CHIROIU Honorific member of Technical Sciences Academy of Romania (ASTR) Ph.D. supervisor in Mechanical Engineering.

\section{Funding Information}

Research contract: Contract number 36-5-4D/1986 from 24IV1985, beneficiary CNST RO (Romanian National Center for Science and Technology) Improving dynamic mechanisms internal combustion engines. 
!All these matters are copyrighted!

Copyrights:

- $\quad$ New Aircraft (New Ionic or Beam Engines): no. 548 of 22-04-2010 [cgiywDssin], Aerospace Engineering

- Some Few Specifications About the Doppler Effect to the Electromagnetic Waves: 636 of 28-05-2010 [iEtcaouxxA], physics

- Presenting an Atomic Model and Some Possible Applications in LASER Field: nr. 639 of 29-052010 [yncngrotfo], physics

- $\quad$ Some Applications in LASER Field: no. 718 of 0907-2010 [xeujouincC], physics

- The Energies of Today and Tomorrow: nr. 819 of 30-09-2010 [kbHquxwykr], energy engineering

- Obtaining Energy by the Annihilation of the Matter with Antimatter - The Battle for Energy: nr. 1068 of 13.03.2011 [GfEqpGDzeh], Energy Engineering

\section{Ethics}

This article is original and contains unpublished material. Authors declare that are not ethical issues and no conflict of interest that may arise after the publication of this manuscript.

\section{References}

Antonescu, P., \& Petrescu, F. (1985). Analytical method of synthesis of cam mechanism and flat stick. In Proceedings of the 4th International Symposium on Theory and Practice of Mechanisms, (TPM'89), Bucharest.

Antonescu, P., \& Petrescu, F. (1989). Contributions to cinetoelastodynamic analysis of distribution mechanisms.

Antonescu, P., Oprean, M., \& Petrescu, F. (1985a). Contributions to the synthesis of oscillating cam mechanism and oscillating flat stick. In Proceedings of the 4th International Symposium on Theory and Practice of Mechanisms, (TPM'85), Bucharest.

Antonescu, P., Oprean, M., \& Petrescu, F. (1985b). At the projection of the oscillate cams, there are mechanisms and distribution variables. In Proceedings of the V-Conference for Engines, Automobiles, Tractors and Agricultural Machines, IEngines and Automobiles, (AMA'85), Brasov.

Antonescu, P., Oprean, M., \& Petrescu, F. (1986). Projection of the profile of the rotating camshaft acting on the oscillating plate with disengagement. In Proceedings of the 3rd National Computer-aided Design Symposium in the field of Mechanisms and Machine Parts, (MMP'86), Brasov.
Antonescu, P., Oprean, M., \& Petrescu, F. (1987). Dynamic analysis of the cam distribution mechanisms. In Proceedings of the 7th National Symposium on Industrial Robots and Space Mechanisms, (RSM'87), Bucharest.

Antonescu, P., Oprean, M., \& Petrescu, F. (1988). Analytical synthesis of Kurz profile, rotating the flat cam. Mach, Build. Rev.

Antonescu, P., Petrescu, F., \& Antonescu, O. (1994). Contributions to the synthesis of the rotating cam mechanism and the tip of the balancing tip.

Antonescu, P., Petrescu, F., \& Antonescu, D. (1997). Geometrical synthesis of the rotary cam and balance tappet mechanism. Bucharest, 3, 23-23.

Antonescu, P., Petrescu, F., \& Antonescu, O. (2000a). Contributions to the synthesis of the rotary disc-cam profile. In Proceedings of the 8th International Conference on the Theory of Machines and Mechanisms, (TMM'00), Liberec, Czech Republic (pp. 51-56).

Antonescu, P., Petrescu, F., \& Antonescu, O. (2000b). Synthesis of the rotary cam profile with balance follower. In Proceedings of the 8th Symposium on Mechanisms and Mechanical Transmissions, (MMT’00), Timişoara (pp. 39-44).

Antonescu, P., Petrescu, F., \& Antonescu, O. (2001). Contributions to the synthesis of mechanisms with rotary disc-cam. In Proceedings of the 8th IFToMM International Symposium on Theory of Machines and Mechanisms, (TMM'01), Bucharest, ROMANIA (pp. 31-36).

Aversa, R., Petrescu, R. V., Apicella, A., \& Petrescu, F. I. (2017a). Nano-diamond hybrid materials for structural biomedical application. American Journal of Biochemistry and Biotechnology, 13(1), 34-41.

Aversa, R., Petrescu, R. V., Akash, B., Bucinell, R., Corchado, J., Chen, G., ... \& Petrescu, F. I. (2017b). Kinematics and forces to a new model forging manipulator. American Journal of Applied Sciences, 14(1), 60-80.

Aversa, R., Petrescu, R. V., Apicella, A., Petrescu, F. I., Calautit, J. K., Bucinell, R., \& Akash, B. (2017c). Something about the $\mathrm{V}$ engines design. American Journal of Applied Sciences, 14(1), 34-52.

Aversa, R., Parcesepe, D., Petrescu, R. V., Berto, F., Chen, G., Petrescu, F. I., ... \& Apicella, A. (2017d). Processability of bulk metallic glasses. American Journal of Applied Sciences, 14(2), 294-301.

Aversa, R., Petrescu, F. I., Petrescu, R. V., \& Apicella, A. (2016a). Biomimetic finite element analysis bone modeling for customized hybrid biological prostheses development. American Journal of Applied Sciences, 13(11), 1060-1067. 
Aversa, R., Parcesepe, D., Petrescu, R. V. V., Chen, G., Petrescu, F. I. T., Tamburrino, F., \& Apicella, A. (2016b). Glassy amorphous metal injection molded induced morphological defects.

Aversa, R., Petrescu, R. V., Petrescu, F. I., \& Apicella, A. (2016c). Smart-factory: Optimization and process control of composite centrifuged pipes. American Journal of Applied Sciences, 13(11), 1330-1341.

Aversa, R., Tamburrino, F., Petrescu, R. V., Petrescu, F. I., Artur, M., Chen, G., \& Apicella, A. (2016d). Biomechanically inspired shape memory effect machines driven by muscle like acting NiTi alloys. American Journal of Applied Sciences, 13(11), 1264-1271.

Babu, K. V., Rao, A. S., Kumar, K. N., \& Rao, M. V. (2019). Spectral and luminescence properties of manganese doped sodium lead alumino borosilicate glass system. Journal of Aircraft and Spacecraft Technology, 3(1), 248-255.

Babu, K. V., Subba Rao, A., Madhuri, V., \& Suresh, K. (2020). White light generation in Dy3+-doped sodium lead alumino borosilicate glasses for WLED applications. Journal of Aircraft and Spacecraft Technology. 4(1), 39-47.

Brewer, G. D. (1991). Hydrogen aircraft technology. CRC press.

Brischetto, S., \& Torre, R. (2020). Honeycomb Sandwich Specimens Made of PLA and Produced Via 3D FDM Printing Process: An Experimental Study.

Cao, W., Ding, H., Zi, B., \& Chen, Z. (2013). New structural representation and digital-analysis platform for symmetrical parallel mechanisms. International Journal of Advanced Robotic Systems, 10(5), 243.

Chaudhary, S., \& Kumar, A. (2019). Control of twin rotor MIMO system using PID and LQR controller. Journal of Aircraft and Spacecraft Technology, 3(1), 211-220.

de Lima, M. S. F., de Mota Siqueira, R. H., de Carvalho, S. M., \& Abdalla, A. J. (2019). Hardening Effects of In-Situ Aging for a Laser Welded Maraging Steel.

Dong, H., Giakoumidis, N., Figueroa, N., \& Mavridis, N. (2013). Approaching behaviour monitor and vibration indication in developing a General Moving Object Alarm System (GMOAS). International Journal of Advanced Robotic Systems, 10(7), 290.

Franklin, D. J. (1930). Ingenious mechanisms for designers and inventors.

He, B., Wang, Z., Li, Q., Xie, H., \& Shen, R. (2013). An analytic method for the kinematics and dynamics of a multiple-backbone continuum robot. International Journal of Advanced Robotic Systems, 10(1), 84.
Kisabo, A. B., Adebimpe, A. F., \& Samuel, S. O. (2019a). Pitch Control of a Rocket with a Novel LQG/LTR Control Algorithm.

Kisabo, A. B., Nwokolo, N., Adebimpe, A. F., \& Samuel, S. O. (2019b). Novel Approach for Characterizing Solid Rocket Motor (SRM).

Kisabo, A. B., \& Adebimpe, A. F. (2019). State-Space Modeling of a Rocket for Optimal Control System Design. In Ballistics. IntechOpen.

Kosambe, S. (2019a). NASA's exploration missions to the red planet. Journal of Aircraft and Spacecraft Technology. 3(1), 154-171.

Kosambe, S. (2019b). Mission Shakti aka Project XSV1: India's First Anti-Satellite Test (ASAT).

Kosambe, S. (2019c). Overview of Space Debris Mitigation Activities in ISRO.

Kosambe, S. (2019d). Chandrayaan-2: India's second lunar exploration mission. Journal of Aircraft and Spacecraft Technology, 3(1), 221-236.

Langston, L. S. (2016). Hot Plates. Mechanical Engineering, 138(03), 42-47.

Langston, L. S. (2015). Gas Turbines-Major Greenhouse Gas Inhibitors. Mechanical Engineering, 137(12), 54-55.

Lee, B. J. (2013). Geometrical derivation of differential kinematics to calibrate model parameters of flexible manipulator. International Journal of Advanced Robotic Systems, 10(2), 106.

Lin, W., Li, B., Yang, X., \& Zhang, D. (2013). Modelling and control of inverse dynamics for a 5DOF parallel kinematic polishing machine. International Journal of Advanced Robotic Systems, 10(8), 314.

Liu, H., Zhou, W., Lai, X., \& Zhu, S. (2013). An efficient inverse kinematic algorithm for a PUMA560-structured robot manipulator. International Journal of Advanced Robotic Systems, 10(5), 236.

Mishra, A. (2020a). Image Processing of Friction Stir Welded 6060-T5 Aluminum Alloy Joint.

Mishra, A. (2020b). Machine Learning Approach for Defects Identification in Dissimilar Friction Stir Welded Aluminium Alloys AA 7075-AA 1100 Joints.

Oni, M. O., \& Jha, B. K. (2019). Heat Generation/absorption effect on natural convection flow in a vertical annulus with time-periodic boundary conditions. Journal of Aircraft and Spacecraft Technology, 3(1), 183-196.

Padula, F., \& Perdereau, V. (2013). An on-line path planner for industrial manipulators. International Journal of Advanced Robotic Systems, 10(3), 156.

Perumaal, S. S., \& Jawahar, N. (2013). Automated trajectory planner of industrial robot for pick-andplace task. International Journal of Advanced Robotic Systems, 10(2), 100. 
Petrescu, F., \& Petrescu, R. (1995a). Contributions to optimization of the polynomial motion laws of the stick from the internal combustion engine distribution mechanism. Bucharest, 1, 249-256.

Petrescu, F., \& Petrescu, R. (1995b). Contributions to the synthesis of internal combustion engine distribution mechanisms. Bucharest, 1, 257-264.

Petrescu, F., \& Petrescu, R. (1997a). Dynamics of cam mechanisms (exemplified on the classic distribution mechanism). Bucharest, 3, 353-358.

Petrescu, F., \& Petrescu, R. (1997b). Contributions to the synthesis of the distribution mechanisms of internal combustion engines with a Cartesian coordinate method. Bucharest, 3, 359-364.

Petrescu, F., \& Petrescu, R. (1997c). Contributions to maximizing polynomial laws for the active stroke of the distribution mechanism from internal combustion engines. Bucharest, 3, 365-370.

Petrescu, F., \& Petrescu, R. (2000a). Synthesis of distribution mechanisms by the rectangular (Cartesian) coordinate method. University of Craiova, Craiova.

Petrescu, F., \& Petrescu, R. (2000b). The design (synthesis) of cams using the polar coordinate method (triangle method). University of Craiova, Craiova.

Petrescu, F., \& Petrescu, R. (2002a). Motion laws for cams. In Proceedings of the International Computer Assisted Design, National Symposium with Participation,(SNP'02), Braşov (pp. 321-326).

Petrescu, F., \& Petrescu, R. (2002b). Camshaft dynamics elements. In Proceedings of the International Computer Assisted Design, National Participation Symposium,(SNP'02), Braşov (pp. 327-332).

Petrescu, F., \& Petrescu, R. (2003). Some elements regarding the improvement of the engine design. In Proceedings of the National Symposium, Descriptive Geometry, Technical Graphics and Design,(GTD'03), Braşov (pp. 353-358).

Petrescu, F. I., \& Petrescu, R. V. (2005a). The cam design for a better efficiency. Available at SSRN 3076805 .

Petrescu, F. I., \& Petrescu, R. V. (2005b, September). Contributions at the Dynamic of Cams. In The Ninth IFTOMM International Symposium on Theory of Machines and Mechanisms.

Petrescu, F. I., \& Petrescu, R. V. (2005c). Determining the dynamic efficiency of cams. Available at SSRN 3076802 .

Petrescu, F. I., \& Petrescu, R. V. (2005d). An original internal combustion engine. In The Ninth IFTOMM International Symposium on Theory of Machines and Mechanisms.
Petrescu, R. V., \& Petrescu, F. I. (2005e). Determining the mechanical efficiency of Otto engine's mechanism. Available at SSRN 3076804.

Petrescu, R. V., Petrescu, F. I., \& Popescu, N. (2007). Determining gear efficiency. Gear Solutions.

Petrescu, F., \& Petrescu, R. (2011a). Mechanical Systems, Serial and Parallel. Lulu. com.

Petrescu, F. I. T., \& Petrescu, R. V. (2011b). Trenuri planetare. Createspace Independent Pub, 104.

Petrescu, F. I., \& Petrescu, R. V. (2011c). Determination of the Mechanical Efficiency of the Gears. INGINERIA AUTOMOBILULUI, (19), 22-23.

Petrescu, F. I., \& Petrescu, R. V. (2012a). Kinematics of the planar quadrilateral mechanism.

Petrescu, F. I., \& Petrescu, R. V. (2012b). Mecatronicasisteme seriale si paralele.

Petrescu, F. I., \& Petrescu, R. V. (2013a). Cinematics of the $3 R$ Dyad.

Petrescu, F. I., \& Petrescu, R. V. (2013b). Cams with high efficiency. Int. Rev. Mech. Eng, 7(4), 599-606.

Petrescu, F. I. T., \& Petrescu, R. V. (2013c). An algorithm for setting the dynamic parameters of the classic distribution mechanism. Int. Rev. Modell. Simulat, 6, 1637-1641.

Petrescu, F. I., \& Petrescu, R. V. (2013d). Dynamic synthesis of the rotary cam and translated tappet with roll. Engevista, 15(3).

Petrescu, F. I., \& Petrescu, R. V. (2013e). Forces and efficiency of cams. Int. Rev. Mech. Eng, 7(3), 507-511.

Petrescu, F. I. T., \& Petrescu, R. V. V. (2014a). High efficiency gear. Facta Universitatis, Series: Mechanical Engineering, 12(1), 51-60.

Petrescu, F. I., \& Petrescu, R. V. (2014b). Cam gears dynamics in the classic distribution. Independent Journal of Management \& Production (IJM\&P), 5(1).

Petrescu, F. I., \& Petrescu, R. V. (2014c). High efficiency gears synthesis by avoid the interferences. Independent Journal of Management \& Production (IJM\&P), 5(2).

Petrescu, F. I. T., \& Petrescu, R. V. (2014d). Balancing otto engines. Int. Rev. Mech. Eng, 8, 473-480.

Petrescu, F. I. T., \& Petrescu, R. V. (2014e). Machine equations to the classical distribution. Int. Rev. Mech. Eng, 8, 309-316.

Petrescu, F. I. T., \& Petrescu, R. V. (2014f). Forces of internal combustion heat engines. Int. Rev. Modell. Simulat, 7, 206-212.

Petrescu, F. I. T., \& Petrescu, R. V. (2014g). Determination of the yield of internal combustion thermal engines. Int. Rev. Mech. Eng, 8, 62-67. 
Petrescu, F. I., \& Petrescu, R. V. (2014h). Cam Dynamic Synthesis. Al-Khwarizmi Engineering Journal, 10(1), 1-23.

Petrescu, F. I., \& Petrescu, R. V. (2016a). Parallel moving mechanical systems kinematics.

Petrescu, F. I., \& Petrescu, R. V. (2016b). Direct and inverse kinematics to the anthropomorphic robots.

Petrescu, F. I., \& Petrescu, R. V. (2016c). Dynamic cinematic to a structure 2R. GEINTEC Journal, $6(2)$.

Petrescu, F. I. T., \& Petrescu, R. V. V. (2019a). An algorithm to determining the gear efficiency to a simple planetary train. Independent Journal of Management \& Production, 10(5), 1392-1404.

Petrescu, R. V., \& Petrescu, F. I. (2019b). StructuralTopological Synthesis of Space Mechanisms With Rods and Wheels. Independent Journal of Management \& Production (IJM\&P) v, 10.

Petrescu, F. I. T., \& Petrescu, R. V. V. (2019c). Application to rigid memory mechanisms of a variable internal dynamic damping model. Independent Journal of Management \& Production, 10(6), 1994-2022.

Petrescu, F. I., Grecu, B., Comanescu, A., \& Petrescu, R. V. (2009, October). Some mechanical design elements. In The 3rd International Conference on Computational Mechanics and Virtual Engineering COMEC (pp. 29-30).

Petrescu, F.I.T., 2011. Teoria Mecanismelor si a Masinilor: Curs Si Aplicatii. 1st Edn., CreateSpace Independent Publishing Platform. ISBN-10: 1468015826. pp: 432.

Petrescu, F. I. T. (2012). Cold nuclear fusion. Plasma Phys. Fusion Technol. 44, 100-100.

Petrescu, R. V. V. (2019a). Giant success for NASA when the InSight probe has reached "safety" on Mars. Journal of Aircraft and Spacecraft Technology. 3(1), 1-10.

Petrescu, R. V. V. (2019b). Mars Could have Enough Molecular Oxygen to Support Life. Journal of Aircraft and Spacecraft Technology, 3(1), 11-23.

Petrescu, R. V. V. (2019c). About Boeing X-32. Journal of Aircraft and Spacecraft Technology, 3(1), 38-54.

Petrescu, R. V. V. (2019d). China Launches Its First Passenger Aircraft. Journal of Aircraft and Spacecraft Technology, 3, 64-77.

Petrescu, R. V. V. (2019e). NASA and the Conquest of Cosmic Space by Man. Journal of Aircraft and Spacecraft Technology, 3, 78-91.

Petrescu, R. V. V. (2019f). 'Defiant', A Today Unique Helicopter in the World. Journal of Aircraft and Spacecraft Technology, 3, 92-106.
Petrescu, R. V. V. (2019g). The TESS Satellite Will Search for Planets in the Vicinity of Our Solar System. Journal of Aircraft and Spacecraft Technology, 3, 107-118.

Petrescu, R. V. V. (2019h). Boeing's Autonomous Military Aircraft. Journal of Aircraft and Spacecraft Technology, 3, 138-153.

Petrescu, F. I. T. (2019i). About the nuclear particles' structure and dimensions. Computational Particle Mechanics, 6(2), 191-194.

Petrescu, F. I., Apicella, A., Petrescu, R. V., Kozaitis, S., Bucinell, R., Aversa, R., \& Abu-Lebdeh, T. (2016). Environmental protection through nuclear energy. American Journal of Applied Sciences, 13(9), 941-946.

Petrescu, R. V., Aversa, R., Akash, B., Bucinell, R., Corchado, J., Apicella, A., \& Petrescu, F. I. (2017a). Modern propulsions for aerospace-a review. Journal of Aircraft and Spacecraft Technology, 1(1).

Petrescu, R. V., Aversa, R., Akash, B., Bucinell, R., Corchado, J., Apicella, A., \& Petrescu, F. I. (2017b). Modern propulsions for aerospace-part II. Journal of Aircraft and Spacecraft Technology, 1(1).

Petrescu, R. V., Aversa, R., Akash, B., Bucinell, R., Corchado, J., Apicella, A., \& Petrescu, F. I. (2017c). History of aviation-a short review. Journal of Aircraft and Spacecraft Technology, 1(1).

Petrescu, R. V., Aversa, R., Akash, B., Bucinell, R., Corchado, J., Apicella, A., \& Petrescu, F. I. (2017d). Lockheed martin-a short review. Journal of Aircraft and Spacecraft Technology, 1(1).

Petrescu, R. V., Aversa, R., Akash, B., Corchado, J., Apicella, A., \& Petrescu, F. I. (2017e). Our universe. Journal of Aircraft and Spacecraft Technology, 1(2).

Petrescu, R. V., Aversa, R., Akash, B., Corchado, J., Apicella, A., \& Petrescu, F. I. (2017f). What is a UFO?. Journal of Aircraft and Spacecraft Technology, 1(2).

Petrescu, R. V., Aversa, R., Akash, B., Corchado, J., Berto, F., Mirsayar, M., ... \& Petrescu, F. I. T. (2017g). About bell helicopter FCX-001 concept aircraft-a short review. Journal of Aircraft and Spacecraft Technology, 1(2), 91-96.

Petrescu, R. V., Aversa, R., Akash, B., Corchado, J., Apicella, A., \& Petrescu, F. I. (2017h). Home at airbus. Journal of Aircraft and Spacecraft Technology, 1(2).

Petrescu, R. V., Aversa, R., Akash, B., Corchado, J., Kozaitis, S., Abu-Lebdeh, T., ... \& Petrescu, F. I. (2017i). Airlander. Journal of Aircraft and Spacecraft Technology, 1(2). 
Petrescu, R. V., Aversa, R., Akash, B., Corchado, J., Berto, F., Apicella, A., \& Petrescu, F. I. (2017j). When boeing is dreaming-a review. Journal of Aircraft and Spacecraft Technology, 1(3).

Petrescu, R. V., Aversa, R., Akash, B., Corchado, J., Berto, F., Apicella, A., \& Petrescu, F. I. (2017k). About northrop grumman. Journal of Aircraft and Spacecraft Technology, 1(3).

Petrescu, R. V., Aversa, R., Akash, B., Corchado, J., Berto, F., Apicella, A., \& Petrescu, F. I. (20171). Some special aircraft. Journal of Aircraft and Spacecraft Technology, 1(3).

Petrescu, R. V., Aversa, R., Akash, B., Corchado, J., Berto, F., Apicella, A., \& Petrescu, F. I. (2017m). About helicopters. Journal of Aircraft and Spacecraft Technology, 1(3), 204-223.

Petrescu, R. V., Aversa, R., Akash, B., Berto, F., Apicella, A., \& Petrescu, F. I. (2017n). The modern flight. Journal of Aircraft and Spacecraft Technology, 1(4), 224-233.

Petrescu, R. V., Aversa, R., Akash, B., Berto, F., Apicella, A., \& Petrescu, F. I. (2017o). Sustainable energy for aerospace vessels. Journal of Aircraft and Spacecraft Technology, 1(4), 234-240.

Petrescu, R. V., Aversa, R., Akash, B., Berto, F., Apicella, A., \& Petrescu, F. I. (2017p). Unmanned helicopters. Journal of Aircraft and Spacecraft Technology, 1(4), 241-248.

Petrescu, R. V., Aversa, R., Akash, B., Berto, F., Apicella, A., \& Petrescu, F. I. (2017q). Project HARP. Journal of Aircraft and Spacecraft Technology, 1(4), 249-257.

Petrescu, R. V., Aversa, R., Akash, B., Berto, F., Apicella, A., \& Petrescu, F. I. (2017r). Presentation of Romanian Engineers who Contributed to the Development of Global Aeronautics-Part I. Journal of Aircraft and Spacecraft Technology, 1(4), 258-271.

Petrescu, R. V., Aversa, R., Akash, B., Berto, F., Apicella, A., \& Petrescu, F. I. (2017s). A first-class ticket to the planet mars, please. Journal of Aircraft and Spacecraft Technology, 1(4), 272-281.

Petrescu, R. V., Aversa, R., Li, S., Bucinell, R., Kozaitis, S., Abu-Lebdeh, T., ... \& Petrescu, F. I. (2017s). Electron dimensions. American Journal of Engineering and Applied Sciences, 10(2), 584-602.

Petrescu, R. V., Aversa, R., Kozaitis, S., Apicella, A., \& Petrescu, F. I. (2017u). Deuteron dimensions. American Journal of Engineering and Applied Sciences, 10(3).

Petrescu, R. V., Aversa, R., Kozaitis, S., Apicella, A., \& Petrescu, F. I. (2017v). Some proposed solutions to achieve nuclear fusion. American Journal of Engineering and Applied Sciences, 10(3).
Petrescu, R. V., Aversa, R., Kozaitis, S., Apicella, A., \& Petrescu, F. I. $(2017 \mathrm{w})$. Some basic reactions in nuclear fusion. American Journal of Engineering and Applied Sciences, 10(3).

Petrescu, F. I. T., Petrescu, R. V., \& Mirsayar, M. (2017x). The computer algorithm for machine equations of classical distribution. Journal of Materials and Engineering Structures «JMES», 4(4), 193-209.

Petrescu, R. V., Aversa, R., Apicella, A., Kozaitis, S., Abu-Lebdeh, T., Akash, B., \& Petrescu, F. I. (2017y). Triton for nuclear fusion. American Journal of Engineering and Applied Sciences, 10(4).

Petrescu, R. V., Aversa, R., Apicella, A., \& Petrescu, F. I. (2018a). Romanian Engineering'On the Wings of the Wind'. Journal of Aircraft and Spacecraft Technology, 2(1), 1-18.

Petrescu, R. V., Aversa, R., Apicella, A., \& Petrescu, F. I. (2018b). NASA Data used to discover eighth planet circling distant star. Journal of Aircraft and Spacecraft Technology, 2(1), 19-30.

Petrescu, R. V., Aversa, R., Apicella, A., \& Petrescu, F. I. (2018c). NASA has found the most distant black hole. Journal of Aircraft and Spacecraft Technology, 2(1), 31-39.

Petrescu, R. V., Aversa, R., Apicella, A., \& Petrescu, F. I. (2018d). Nasa selects concepts for a new mission to titan, the moon of saturn. Journal of Aircraft and Spacecraft Technology, 2(1), 40-52.

Petrescu, R. V., Aversa, R., Apicella, A., \& Petrescu, F. I. (2018e). NASA sees first in 2018 the direct proof of ozone hole recovery. Journal of Aircraft and Spacecraft Technology, 2(1), 53-64.

Petrescu, R. V., Aversa, R., Apicella, A., \& Petrescu, F. I. (2018f). An Exoplanet has Smothering Stratosphere without Water. Relly Victoria Petrescu et al./Journal of Aircraft and Spacecraft Technology, 2, 65-71.

Petrescu, R. V., Aversa, R., Apicella, A., \& Petrescu, F. I. (2018g). Structure of Buried Ice on Mars. Relly Victoria Petrescu et al./Journal of Aircraft and Spacecraft Technology, 2, 72-79.

Petrescu, N., Aversa, R., Apicella, A., \& Petrescu, F. I. (2018h). A New Exoplanet Reveals its Identity. Nicolae Petrescu et al./Journal of Aircraft and Spacecraft Technology, 2, 85-96.

Petrescu, N., Aversa, R., Apicella, A., \& Petrescu, F. I. (2018i). New Researches Examines the Wing Shapes to Reduce Vortex and Wake. Journal of Aircraft and Spacecraft Technology, 2, 97-110. 
Petrescu, R. V., Aversa, R., Apicella, A., \& Petrescu, F. I. (2018j). Romanian Engineering'On the Wings of the Wind'. Journal of Aircraft and Spacecraft Technology, 2(1), 1-18.

Petrescu, R. V., Aversa, R., Apicella, A., \& Petrescu, F. I. (2018k). NASA Data used to discover eighth planet circling distant star. Journal of Aircraft and Spacecraft Technology, 2(1), 19-30.

Petrescu, R. V., Aversa, R., Apicella, A., \& Petrescu, F. I. (20181). NASA has found the most distant black hole. Journal of Aircraft and Spacecraft Technology, 2(1), 31-39.

Petrescu, R. V., Aversa, R., Apicella, A., \& Petrescu, F. I. (2018m). Nasa selects concepts for a new mission to titan, the moon of saturn. Journal of Aircraft and Spacecraft Technology, 2(1), 40-52.

Petrescu, R. V., Aversa, R., Apicella, A., \& Petrescu, F. I. (2018n). NASA sees first in 2018 the direct proof of ozone hole recovery. Journal of Aircraft and Spacecraft Technology, 2(1), 53-64.

Petrescu, R. V., Aversa, R., Apicella, A., \& Petrescu, F. I. (2018o). Modern propulsions for the aerospace industry. American Journal of Engineering and Applied Sciences, 11(2), 715-755.

Petrescu, R. V., Aversa, R., Apicella, A., Kozaitis, S., Abu-Lebdeh, T., \& Petrescu, F. I. (2018p). Inverse kinematics of a stewart platform. Journal of Mechatronics and Robotics, 2(1), 45-59.

Petrescu, F. I., \& Calautit, J. K. (2016a). About nano fusion and dynamic fusion. American Journal of Applied Sciences, 13(3).

Petrescu, F. I., \& Calautit, J. K. (2016b). About the light dimensions. American Journal of Applied Sciences, 13(3).

Petrescu, R. V. V. (2020). British Airways is Ordering up to 42 Boeing 777-9s Aeronaves to Modernize the UK Flag Carriers Long-Haul Fleet.

Petrescu, R. V. V., \& Petrescu, F. I. T. (2020). About gateway. Journal of Aircraft and Spacecraft Technology. 4(1), 70-87.

Petrescu, R. V. V., Aversa, R., \& Apicella, A. (2020) Structural colour from optical phenomena caused by interference with a thin or multilayer film, photonic nanocrystals, light scattering and diffraction grating effect. Journal of Aircraft and Spacecraft Technology. 4(1), 117-143.

Rahman, Z. A. (2018). On a New Equation for the Design and Development of Space Launch Vehicles. Journal of Aircraft and Spacecraft Technology, 2(1), 80-84.

Sharma, A., \& Kosambe, S. (2020). Trajectory optimization for first human asteroid exploration mission. Journal of Aircraft and Spacecraft Technology. 4(1), 96-116. de Mota Siqueira, R. H., Atilio, I., de Andrade Ferreira, C. C., de Carvalho, S. M., \& de Lima, M. S. F. (2020). Fiber Laser Beam Welding Between Niobium and Titanium.

Svensson, F., Hasselrot, A., \& Moldanova, J. (2004). Reduced environmental impact by lowered cruise altitude for liquid hydrogen-fuelled aircraft. Aerospace Science and Technology, 8(4), 307-320.

Tumino, D. (2020). mathematical formulation and numerical implementation of a finite element with anisotropic geometry. Journal of Aircraft and Spacecraft Technology. 4(1), 26-38.

\section{Source of Figures:}

Fig. 1

https://en.wikipedia.org/wiki/Concorde\#/media/File:

British_Airways_Concorde_G-BOAC_03.jpg

Fig. 2

https://www.universetoday.com/wp-

content/uploads/2011/05/reaction-engines-skylon-spaceplane-4-537x402.jpg

Fig. 3

https://en.wikipedia.org/wiki/Lockheed_SR-

71_Blackbird\#/media/File:Lockheed_SR-

71_Blackbird.jpg

Fig. 4

https://upload.wikimedia.org/wikipedia/commons/7/7 7/F-18-diamondback_blast.jpg

Fig. 5

https://en.wikipedia.org/wiki/Supersonic_aircraft\#/m edia/File:A_B-1_Lancer_performs_a_fly-

by_during_a_firepower_demonstration.jpg

Fig. 6

https://ro.wikipedia.org/wiki/F-

111_Aardvark\#/media/Fi\%C8\%99ier:F-

111_Red_Flag_09.jpg

Fig. 7

https://ro.wikipedia.org/wiki/F-

15_Eagle\#/media/Fi\%C8\%99ier:F-

15,_71st_Fighter_Squadron,_in_flight.JPG

Fig. 8

https://static.playtech.ro/wp-

content/uploads/2017/03/XB-70.jpg

Fig. 9

https://storage0.dms.mpinteractiv.ro/media/1/1/7627/ 8607752/1/avion.jpg?width=560

Fig. 10

https://www.digi24.ro/stiri/sci-tech/virgin-galactic-sirolls-royce-construiesc-un-avion-supersonic-calatoriivor-ajunge-de-la-new-york-la-londra-in-mai-putin-de-2ore-1347888 
Relly Victoria Virgil Petrescu / American Journal of Engineering and Applied Sciences 2020, 13 (3): 451.476 DOI: 10.3844/ajeassp.2020.451.476

Annex: Some supersonic aircraft are shown in Figures 1-10.

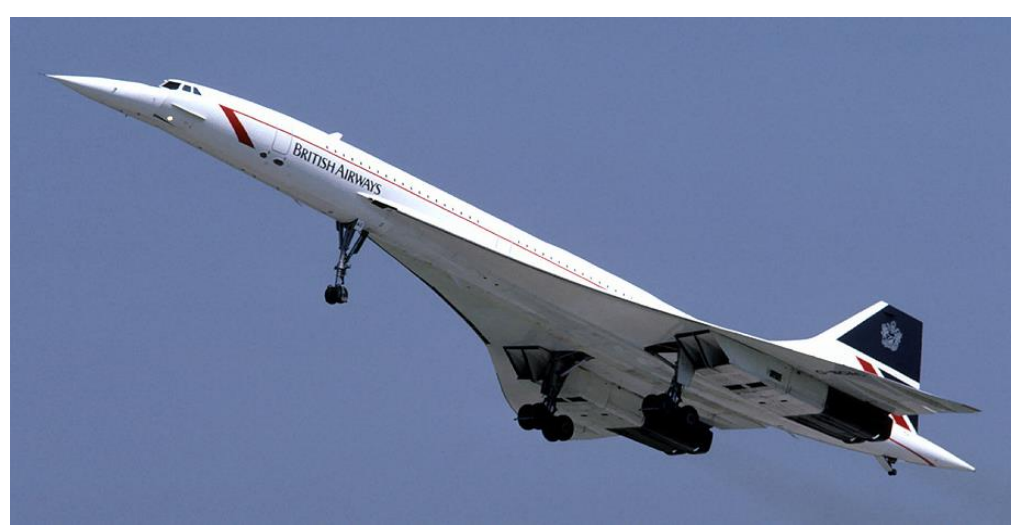

Fig. 1: British Airways Concorde G-BOAC

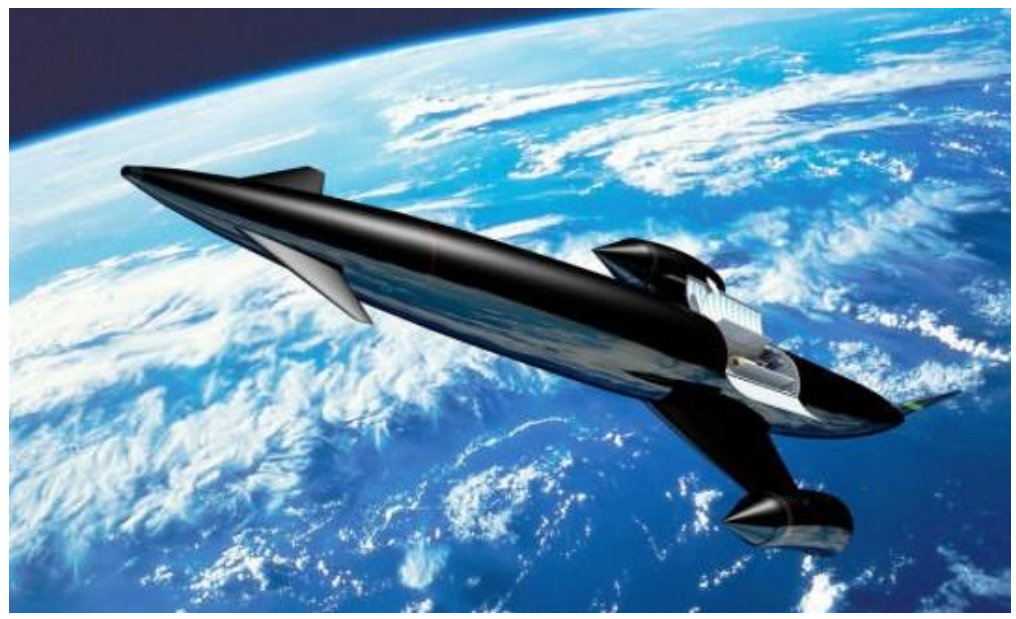

Fig. 2: British Skylon Aircraft

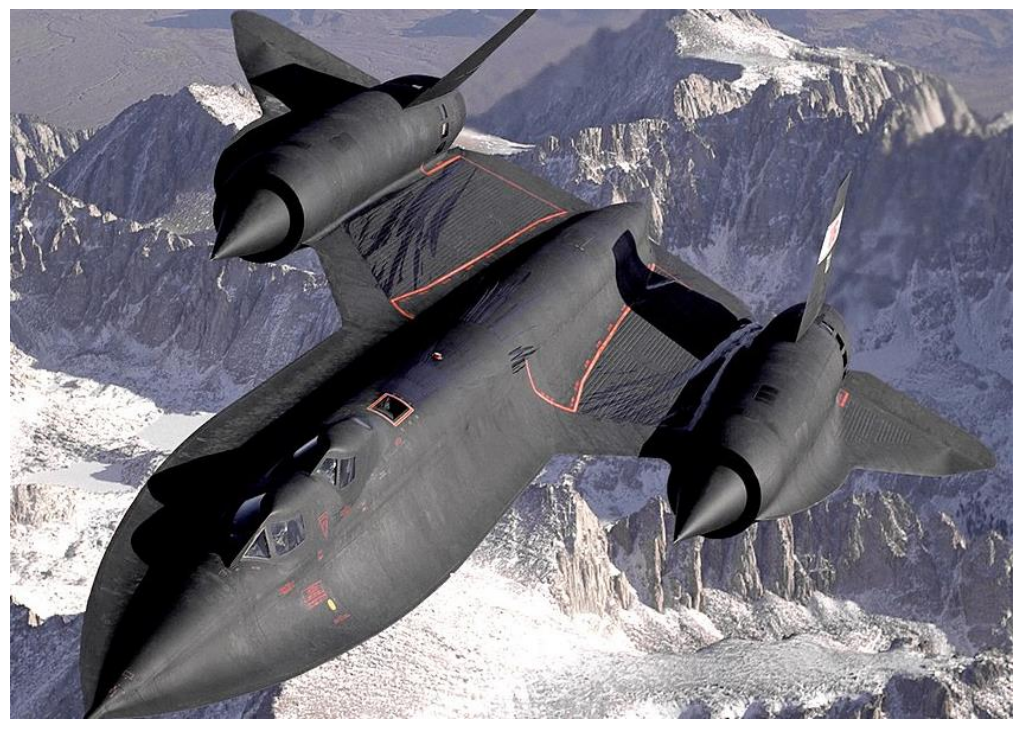

Fig. 3: SR-71B Blackbird, NASA 831 
Relly Victoria Virgil Petrescu / American Journal of Engineering and Applied Sciences 2020, 13 (3): 451.476 DOI: 10.3844/ajeassp.2020.451.476

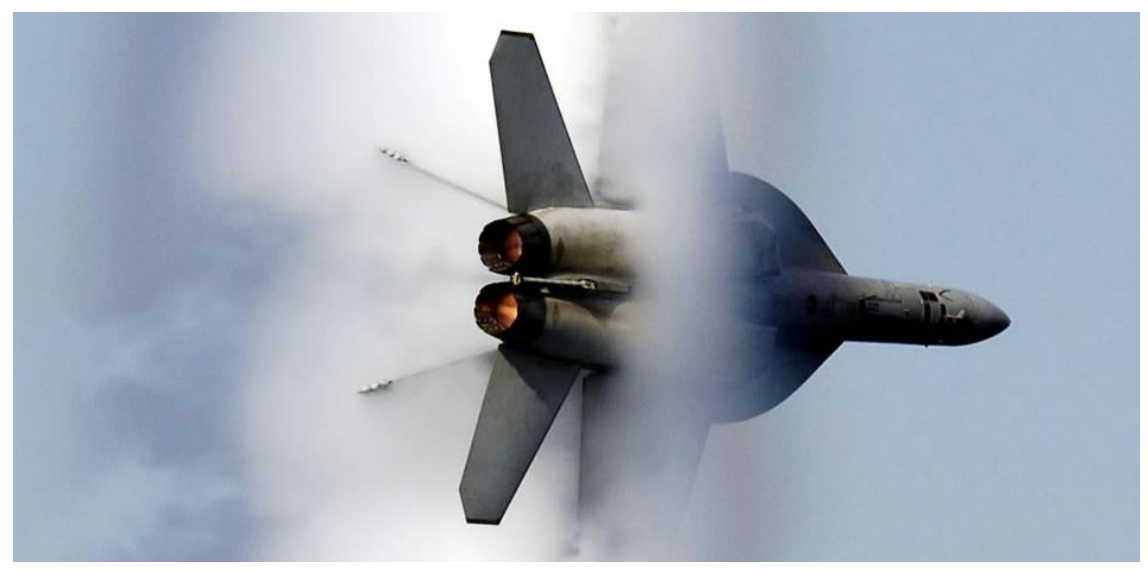

Fig. 4: United States Navy F/A-18F Super Hornet in transonic flight

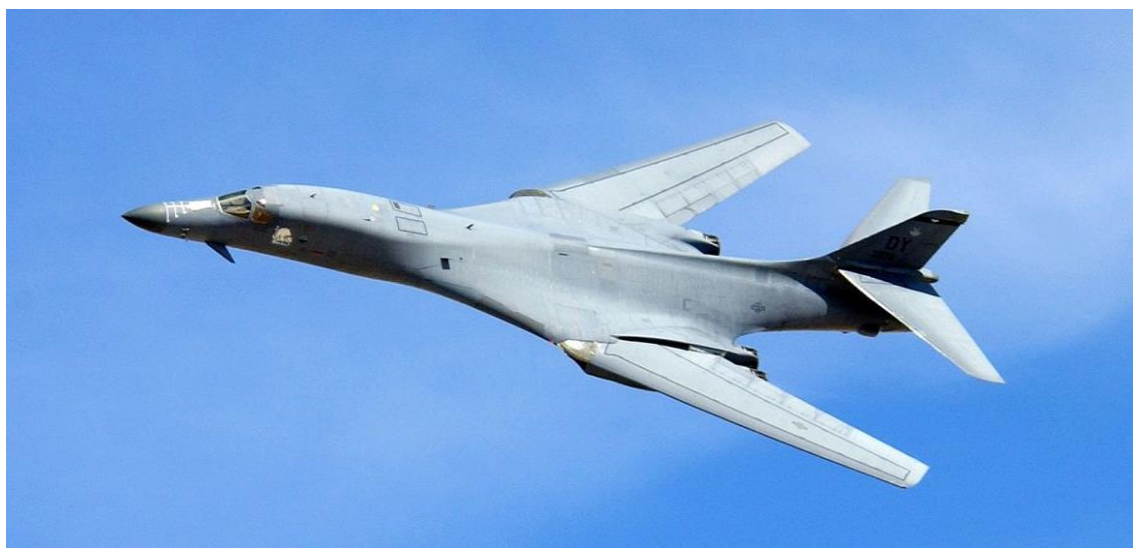

Fig. 5: United States B-1B Lancer

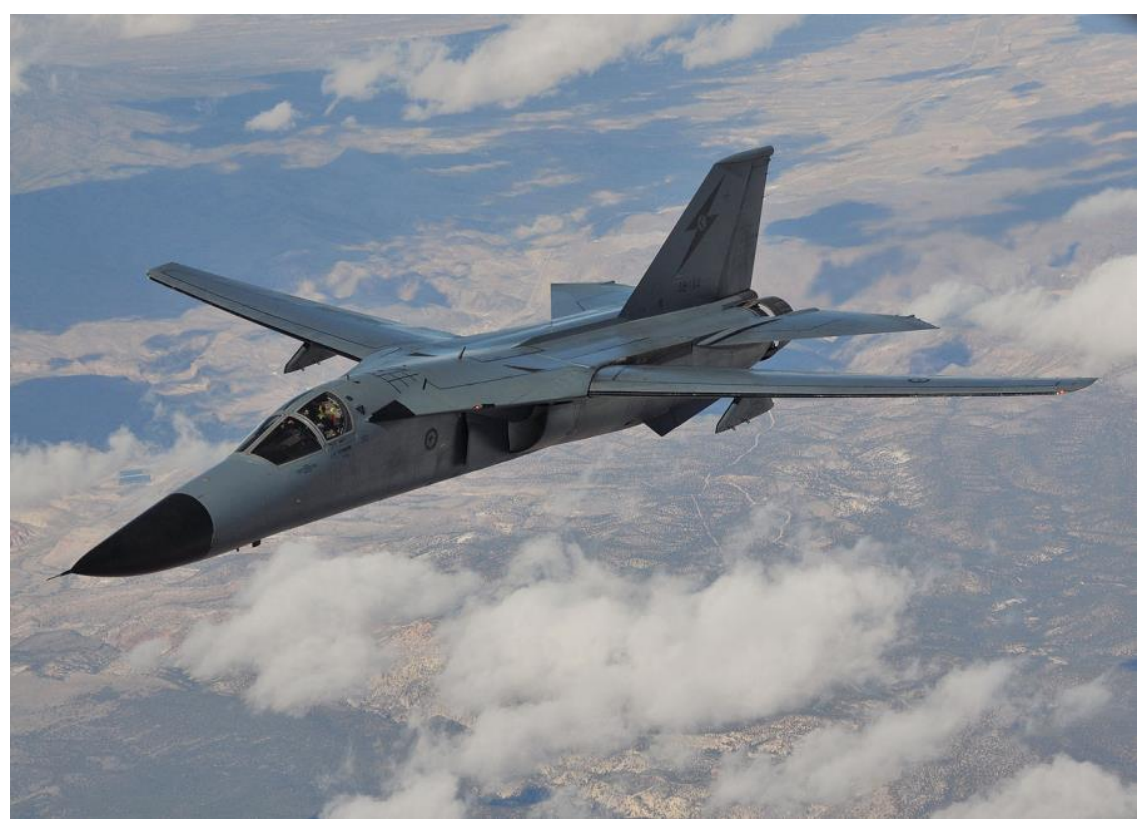

Fig. 6: General Dynamics F-111 is a medium-range strategic bomber 


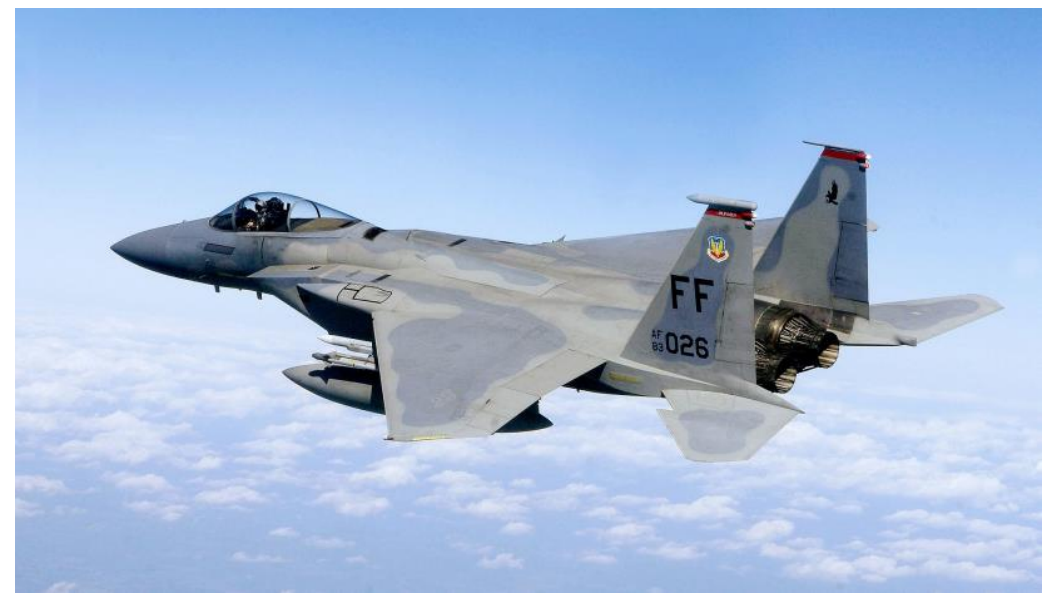

Fig. 7: The F-15 Eagle produced by McDonnell Douglas (Boeing, after joining in 1997) is a twin-engine post-combustion aircraft, capable of flying at night, in all weather conditions, designed to penetrate enemy airspace, to obtain and maintain air superiority

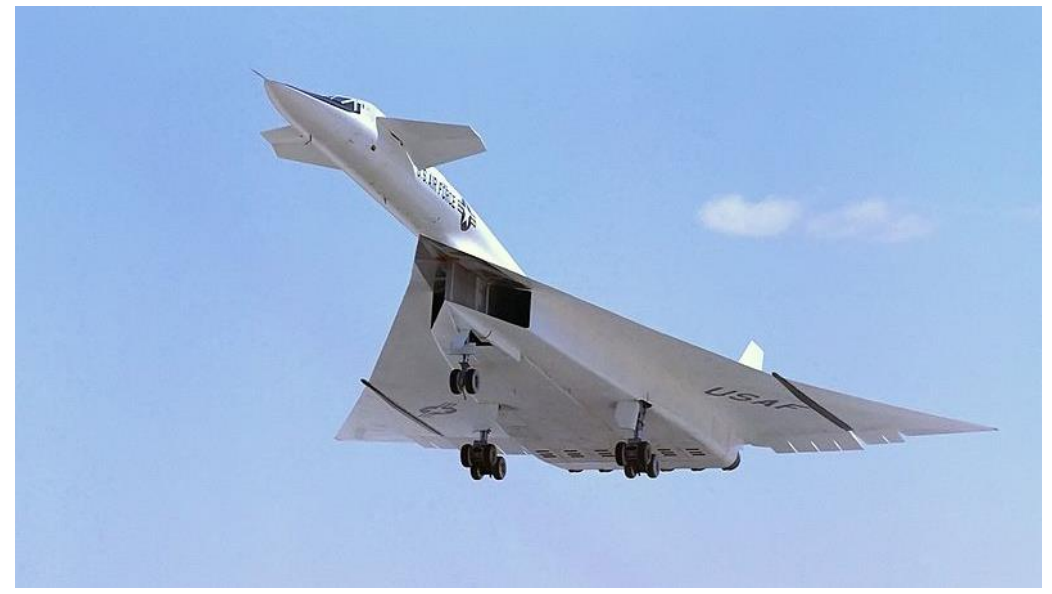

Fig. 8: North American XB-70 "Valkyrie" was the prototype of a highly advanced strategic bomber, of high altitude and speed (Mach 3)

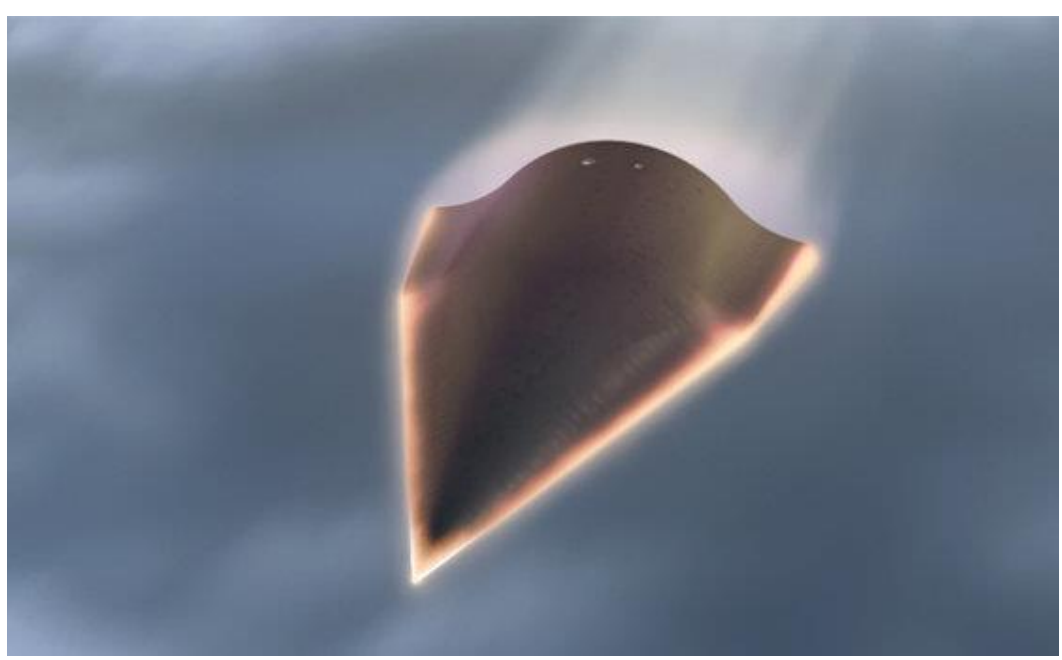

Fig. 9: Falcon HTV-2 
Relly Victoria Virgil Petrescu / American Journal of Engineering and Applied Sciences 2020, 13 (3): 451.476 DOI: 10.3844/ajeassp.2020.451.476

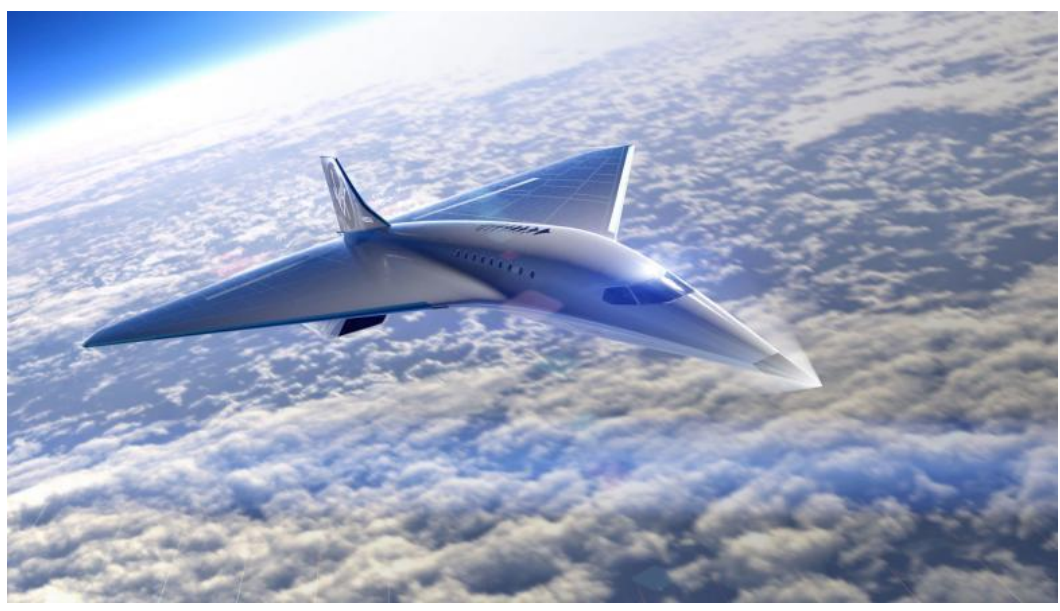

Fig. 10: Virgin Galactic and Rolls Royce build a supersonic aircraft 